\title{
Modelación y co-movimientos de la tasa de cambio colombiana, 2011-2017
}

\author{
MAYA SIERRA, GIULIANA \\ Departamento de Ingeniería Financiera \\ Universidad de Medellín (Colombia) \\ Correo electrónico: gmayas@ultraserfinco.com \\ MARÍN RODRÍGUEZ, NINI JOHANA \\ Departamento de Economía \\ Universidad de Medellín (Colombia) \\ Correo electrónico: njmarin@udem.edu.co
}

\begin{abstract}
RESUMEN
La tasa de cambio está influenciada por múltiples factores macroeconómicos nacionales e internacionales, lo que genera altos niveles de incertidumbre. El objetivo de esta investigación es la construcción de modelos ARIMA-GARCH y ARIMAX-GARCH como herramienta para el pronóstico de la tasa de cambio en Colombia a partir de los retornos diarios de los precios de cierre USD/COP y su análisis de correlación dinámica con algunas variables de interés. Los resultados sugieren que la incorporación de variables exógenas significativas dentro de la modelación ARIMAX-GARCH con correlación persistente según el modelo DCC (por sus siglas en inglés Dinamic Conditional Correlation) al par USD/COP genera pronósticos fuera de muestra con mejor desempeño que los modelos univariados ARIMA-GARCH.
\end{abstract}

Palabras clave: variables macroeconómicas, modelos de pronóstico, tasa de cambio, correlación.

Clasificación JEL: E6; C51; F31; C30.

MSC2010: 91B64; 91B70; 91B84; 91G70; 62H20. 


\title{
Modeling and comovements of the Colombian exchange rate, 2011-2017
}

\begin{abstract}
The exchange rate is influenced by multiple national and international macroeconomic factors, which generates high levels of uncertainty. The objective of this research is the construction of ARIMA-GARCH and ARIMAXGARCH models as a tool for the forecast of the exchange rate in Colombia from the daily returns of the closing prices USD/COP and its analysis of dynamic correlation with some of the most explicative variables. The results suggest that the incorporation of significant exogenous variables within the ARIMAXGARCH model with persistent correlation according to the DCC (Dinamic Conditional Correlation) model to the USD/COP pair generates out-of-sample forecasts with better performance than the ARIMA-GARCH univariate models.
\end{abstract}

Keywords: Macroeconomic fundamentals, forecast models, exchange rate, correlation. JEL classification: E6; C51; F31; C30.

MSC2010: 91B64; 91B70; 91B84; 91G70; 62H20.

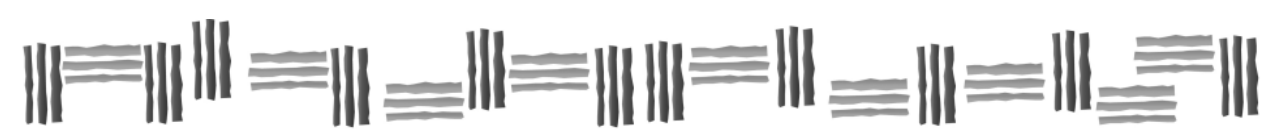




\section{Introducción}

La tasa de cambio en economías con regímenes cambiarios flexibles es más que un término de intercambio de una moneda local frente a otras. Ésta es un indicador que permite evaluar el desempeño de una economía con el resto del mundo, dado que la volatilidad de la misma tiene efectos directos en la economía de un país o región que impacta desde el nivel de flujos de capital, la balanza de cuenta corriente, la inflación y otras variables macroeconómicas que afectan el crecimiento económico. Por esta razón, el entendimiento y pronóstico de esta tasa se ha convertido en foco de interés para académicos, analistas, empresarios de diferentes sectores económicos, inversionistas y gobiernos de los países donde el régimen cambiario tiene algún tipo de flexibilidad. Lo anterior, porque el comportamiento del tipo de cambio va a estar explicado por la configuración de diversas variables macroeconómicas, técnicas, variables macroeconómicas y choques coyunturales en las economías.

La importancia de dichas variables como catalizadores del nivel de tasa de cambio no es estática en el tiempo y esto hace que la esencia del comportamiento de la tasa de cambio en el corto plazo sea un reto para quienes se han preocupado por la generación de modelos eficientes de pronóstico y por la identificación de las variables determinantes de la tasa de cambio en dichas economías, pues para países en los que el régimen cambiario está sujeto a algún tipo de control no tiene sentido hacer ningún tipo de análisis en la medida en que dicha evolución depende de los intereses del gobierno.

Los primeros acercamientos para su pronóstico desde los modelos econométricos se dieron a partir de Meese y Rogoff (1983), quienes demostraron que el modelo de caminata aleatoria es un buen estimador de la tasa de cambio en economías abiertas. En la misma línea Chinn y Meese (1995) compararon los pronósticos por medio de diferentes modelos estructurales como el de Hooper-Morton, entre otros y destacan que se obtienen estadísticamente mejores resultados por medio del modelo de caminata aleatoria para horizontes de corto plazo.

Otros autores (Majhi, Panda, \& Sahoo, 2009; Panda \& Narasimhan, 2007) han realizado afirmaciones acerca de las limitaciones de los modelos lineales para capturar el impacto de asimetrías en las series y comparando los resultados con los alcanzados por medio de modelos como las redes neuronales. Para el caso colombiano Jalil y Misas (2007) indican que a la luz de las funciones de pérdida asimétricas, los modelos no lineales tienen una mejora considerable en capacidad de pronóstico, con respecto a los modelos lineales. Sin embargo, recientemente Pacelli (2012) demuestra que los modelos autorregresivos en varianza ARCH (Modelos Autorregresivos Condicionales Heteroscedásticos) y GARCH (Modelos Generalizados Autorregresivos Condicionales Heteroscedásticos) tienen un mejor desempeño comparado con los modelos de redes neuronales para analizar la dinámica de la tasa de cambio.

De esta manera, conociendo la relevancia que tiene el comportamiento del tipo de cambio, el objetivo de esta investigación es identificar dentro de la familia de los modelos ARIMA-GARCH cuál es el modelo que mejor se ajusta y pronostica la tasa de cambio diaria en Colombia a partir de la serie de retornos diarios para el precio de cierre del par USD/COP y conocer sus co-movimientos con algunas variables macroeconómicas de interés en el período de tiempo seleccionado. Inicialmente el modelo ARIMA (Modelo Autorregresivo integrado de Medias Móviles) propuesto por Box y Jenkins (1970) busca pronosticar series estocásticas estacionarias. Teniendo presente que la mayoría de series financieras violan este supuesto, tal como lo demostró Fama (1965); es necesario transformar la serie hasta obtener un proceso estacionario. El modelo ARIMA está basado en rezagos de la serie temporal estacionaria que incluye los modelos Autorregresivos (o Modelos AR) junto con los errores al estimar el valor de la variable en los períodos anteriores, es decir, los modelos de medias móviles (o Modelos MA, por sus siglas en inglés Moving Average), los cuales son utilizados frecuentemente, dada su eficiente nivel de ajuste ante cambios en la tendencia. Así mismo, teniendo presente que no solo 
el componente autorregresivo es el mejor predictor para las variables financieras se explora el modelo ARIMAX (Modelo Autorregresivo integrado de Medias Móviles con variables exógenas), el cual nace a partir la incorporación de variables independientes o exógenas a un modelo ARIMA permitiendo capturar la correlación con el comportamiento de otras variables. Por último con los modelos GARH se modela la estructura temporal de la varianza, el cual hace parte de la familia de modelos ARCH introducida por Engle (1982) y Bollerslev (1986).

Es así como a partir de un análisis de las variables macroeconómicas y otras series financieras que influyen en la formación de la tasa de cambio para el caso colombiano permiten que el modelo pueda captar la influencia de factores externos y generar pronósticos más precisos, tal como proponen otros autores (Stein \& Allen, 1997; Abhyankar, Sarno \& Valente, 2005; Ehrmann \& Fratzscher, 2005; MacDonald \& Marsh, 1997; Medeiros \& Rossi, 2009; Murcia \& Rojas, 2015).

En esta investigación se realizó un análisis de las principales variables que impactan el nivel del tipo de cambio. El análisis arrojó como variables significativas que permiten explicar su comportamiento para el periodo 1 de enero de 2011 al 15 de mayo de 2017: los TES de vencimiento $2024^{1}$, el índice DXY (por sus siglas en inglés de U.S. Dollar Index) y el precio del petróleo de la referencia WTI (por sus siglas en inglés de West Texas Intermediate) que influyen en la formación de la tasa de cambio, lo cual se contrastó con el uso del modelo de Correlación Condicional Dinámica, DCC, para observar sus co-movimientos con algunas variables macroeconómicas de interés, tales como el Î́ndice DXY, Índice Colcap, CDS 10 años Colombia, Índice IBR, Tesoros con vencimiento 10 años, índice MXEF, WTI, TES con vencimiento 2024, índice VIX, USD/CLP y USD/MXN y se encontró la relación de dependencia lineal en el tiempo.

El documento está dividido en tres partes. En la primera se destacan los aspectos centrales del papel de la tasa de cambio en economías abiertas con tipo de cambio flexible principalmente el caso colombiano, la importancia de su análisis y las variables que permiten determinar la formación de la tasa de cambio en Colombia. En la segunda sección se realiza una descripción general de los modelos ARIMA, ARIMAX y GARCH. En la tercera se presenta un análisis de los datos y se exponen los resultados obtenidos en la aplicación de los modelos para estimación del USD/COP y el análisis de las Correlaciones Condicionales Dinámicas entre el tipo de cambio y el Índice DXY, Índice Colcap, CDS 10 años Colombia, Índice IBR, Tesoros con vencimiento 10 años, índice MXEF, WTI, TES con vencimiento 2024, índice VIX, USD/CLP y USD/MXN para identificar cómo ha evolucionado en los últimos años la relación de dependencia lineal y, por último, se presentan algunas conclusiones.

\section{Marco Teórico.}

\subsection{La importancia de la modelación de la Tasa de Cambio en Colombia.}

El papel del dólar en el mundo no está fundamentado en que es un simple instrumento para transacciones internacionales sino como principal activo de inversión de flujos capital e inversión de las reservas de los Bancos Centrales alrededor del mundo, las cuales son un indicador de solvencia de los países y son un instrumento para intervenir en pro de mantener la estabilidad el mercado cambiario (Tosoni, 2011). Lo anterior, convierte al tipo de cambio frente al dólar en una guía de la realidad económica de los países con tasa de cambio flotantes. Colombia en septiembre de 2000 abandonó el esquema de banda cambiaria, que había operado en el país a partir de septiembre de 1994 (Chavarro, 2008), y a partir de ese momento deja flotar el tipo de cambio, aunque conserva la autonomía para realizar intervenciones puntuales en el

\footnotetext{
${ }^{1}$ Títulos de deuda soberana de Colombia, son la referencia más líquida del mercado de deuda pública. Fueron emitidos por el Ministerio de Hacienda y administrados por el Banco de la República con vencimiento el 24 de julio del 2024.
} 
mercado a través de distintos mecanismos como opciones Put o Call ${ }^{2}$ y la intervención discrecional y las subastas directas (Davis, 2017).

En la medida que la economía mundial ha empezado a salir de la desaceleración económica en la cual se había visto sumergida a raíz de la crisis subprime de Estados Unidos en 2007, donde los capitales abandonaron en gran proporción la economía estadounidense, por su alto nivel de volatilidad y bajas tasas de interés, se presentó un flujo de capitales de portafolio hacia países emergentes que ofrecían una mejor relación riesgo-retorno. Es así como el movimiento de la liquidez mundial le ha dado un protagonismo mayor a la importancia que tiene el dólar en el contexto global y profundizó su impacto en las economías emergentes donde se suman nuevos factores que generan volatilidad.

Sin embargo, una vez que Estados Unidos comenzó a mostrar signos de recuperación y otras potencias como China y Europa presentaron datos de bajo crecimiento, los mercados emergentes no tienen un escenario más promisorio en este sentido. Es por ello que una de las variables a monitorear es los CDS (por sus siglas en inglés Credit Defaul Swap), que son considerados como un indicador de la prima de riesgo comparados con Estados Unidos. Es así, como se muestra en el Gráfico 1 para los principales países de la región como Chile, Perú, México, Brasil y Colombia un fuerte impacto en términos de percepción de riesgo, cuando las señales de recuperación de Estados Unidos y el resto de economías han sido desiguales, convirtiéndose en catalizador de volatilidad. El comportamiento CDS como fuente de información para el mercado de capitales es analizado por diversos autores, entre ellos Hassan, Kayhan y Bayat (2017) que concluye con que el CDS permite explicar el comportamiento de la tasa de cambio en Turquía y en escenario regional Carr y Wu (2007) analizaron la volatilidad del mercado cambiario por medio de la fuerte correlación con los CDS de México y Brasil.

Sumado a esta recuperación, los movimientos en términos de política monetaria por parte de los Bancos centrales, las tensiones geopolíticas y los cambios de líneas gobierno se han traducido en una revaluación del dólar frente al resto de monedas en el mundo, generando más incertidumbre que incrementan los rápidos movimientos de los flujos de inversión, buscando inversiones seguras (Julio \& Yook, 2016).

Gráfico 1. Comportamiento CDS Chile, Perú, México, Brasil y Colombia 2011- Julio de 2017.

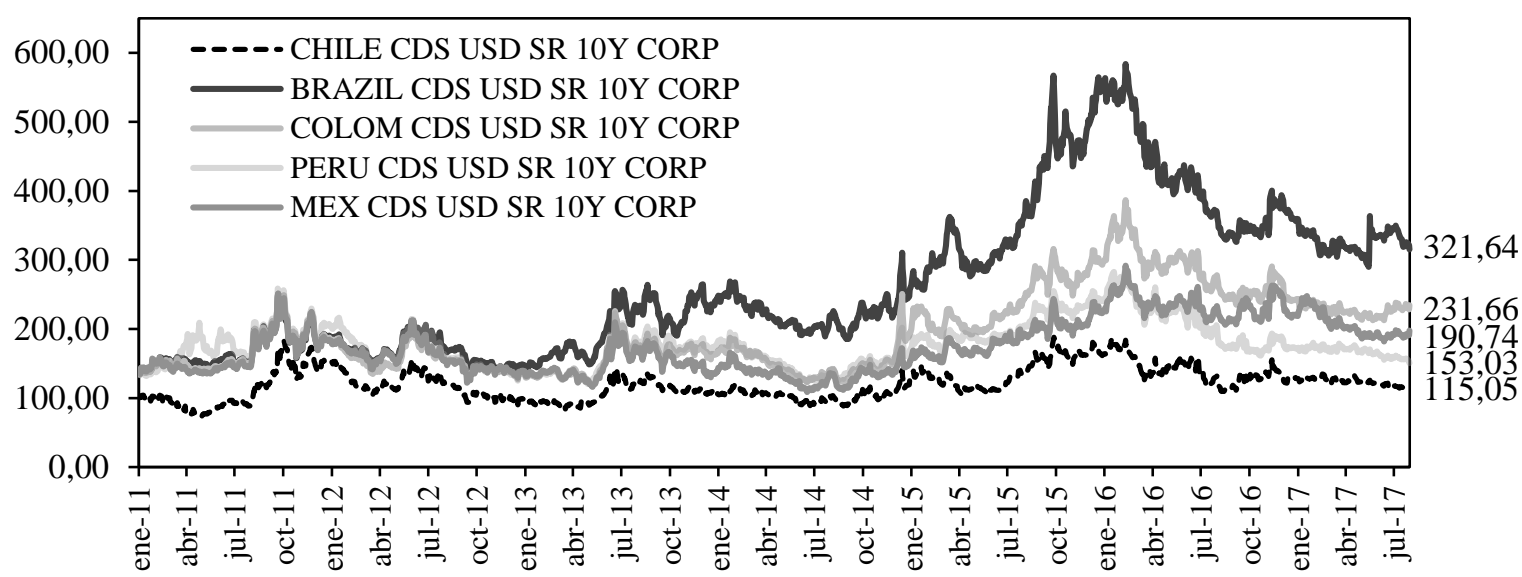

Fuente: Elaboración propia con datos de Bloomberg (2017).

\footnotetext{
${ }^{2}$ Venta de Opciones Put (Venta) y Opciones Call (Compra), instrumentos financieros para acumulación o desacumulación de reservas internacionales y para el control de la volatilidad por parte del Banco de la República.
} 
En el Gráfico 2, se observa el comportamiento que han tenido para el periodo 2000-2017 las monedas de las economías más representativas de Latinoamérica como lo son Colombia, Brasil, Perú, Chile, México y el Índice DXY. Donde se evidencia que, en los períodos posteriores a las crisis norteamericanas, la presión sobre el tipo de cambio por la migración de flujos ha generado una depreciación pronunciada de las monedas locales; como se presentó en la crisis del punto COM que tuvo lugar entre marzo y noviembre del 2001 y para la recesión del 2007 por la crisis Subprime, la cual data de diciembre 2007 hasta junio 2009.

\section{Gráfico 2. Comportamiento de monedas suramericanas frente al dólar 2000 - junio 2017, serie} normalizada.

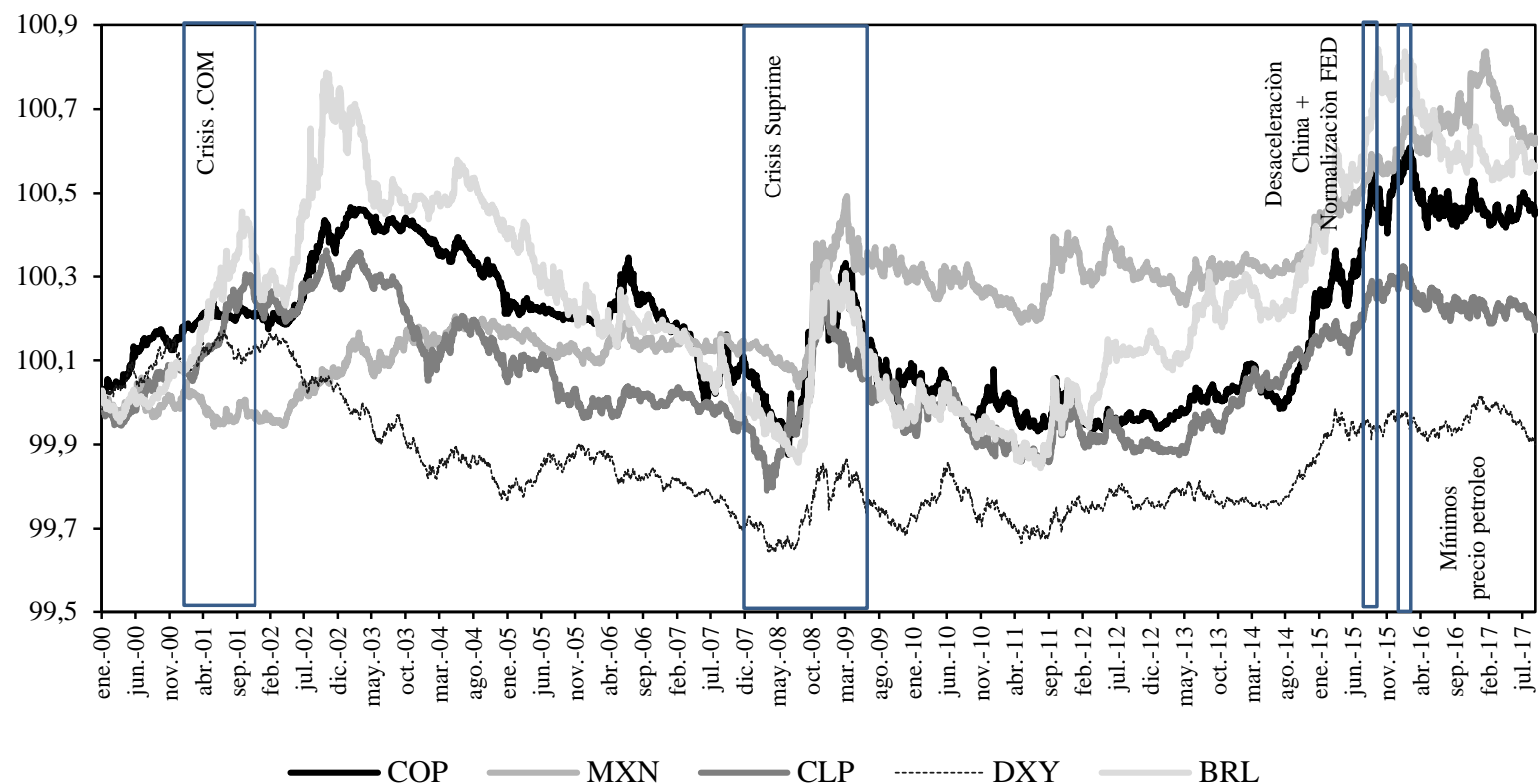

Fuente: Elaboración propia con datos de Bloomberg (2017).

En general, las economías se vieron afectadas por la volatilidad en los precios de petróleo, normalización monetaria por parte de la FED (por sus siglas en inglés Federal Reserve) y la fase de ralentización de la economía China, que siendo uno de los principales demandantes de materias primas a nivel mundial aporta mayor incertidumbre en los precios de los commodities y, por ende, una menor perspectiva de ingresos para las economías emergentes que dependen de ellas, lo que repercute en el valor de sus monedas.

La volatilidad en la tasa de cambio tiene efectos directos en la economía de un país o región, desde el nivel de flujos de capital, la balanza de cuenta corriente, inflación y otras variables macroeconómicas que afectan el crecimiento económico (Cardenas, 1997). Es por esto que se hace necesario un estudio sobre la tasa de cambio, los impactos que pueden tener los diferentes choques externos sobre ésta, y aplicar modelos autorregresivos ARIMA-GARCH y ARIMAX- GARCH, junto con la metodología DCC con el objetivo de explicar su comportamiento en el corto plazo y sus co-movimientos con unas variables macroeconómicas de interés. En la actualidad se encuentra un amplio rango de literatura que se ha preocupado por encontrar la tasa de cambio de equilibrio óptimas para cada una de las economías y a su vez por la generación de modelos que permitan comprender y pronosticar el comportamiento futuro de las mismas. 


\subsection{Variables que influyen en la formación de la tasa de cambio.}

En el sentido de que la tasa de cambio tenga algún tipo de movilidad y flexibilidad, se generan interrogantes sobre qué variables pueden llegar a explicar su comportamiento en términos de depreciación o apreciación frente a la moneda foránea de referencia y de dicha selección depende la eficiencia del modelo.

En este sentido, se han identificado algunas variables que a lo largo de la historia influyen en la trayectoria de corto y largo plazo de las tasas de cambio de las economías con regímenes cambiarios de tipo de cambio flexible. El comportamiento del tipo de cambio en Colombia más que una dinámica de oferta y demanda de mercado, se ve influenciada por las variables macroeconómicas locales e internacionales, activos financieros y movimientos de flujos de capitales internacionales, entre otros.

Tabla 1. Matriz de correlaciones, ventana de tiempo de 1 año corte junio de 2016 a junio de 2017.

\begin{tabular}{|c|c|c|c|c|c|c|c|c|c|c|c|c|c|c|c|c|c|c|}
\hline & COP & MXN & CLP & BRL & $\begin{array}{l}\text { CDS } 10 \\
\text { Años }\end{array}$ & DXY & COLCAP & MXEF & HEES & $\begin{array}{c}\text { Tasa } \\
\text { Intervención }\end{array}$ & IBR & $\begin{array}{c}\text { IPC } \\
\text { Anual } \\
\end{array}$ & $\begin{array}{l}\text { TES } \\
2024 \\
\end{array}$ & WTI & BRENT & VIX & $\begin{array}{l}\text { Tesoros } \\
10 \text { Años }\end{array}$ & $\begin{array}{c}\text { PIB } \\
\text { Trimestral }\end{array}$ \\
\hline $\mathrm{COP}$ & 1 & 0.50 & 0.58 & 0.46 & 0.58 & 0.18 & -0.32 & -0.40 & -0.16 & -0.01 & -0.02 & -0.21 & -0.46 & -0.44 & -0.41 & 0.27 & 0.10 & 0.71 \\
\hline MXN & 0.498 & 1 & 0.37 & 0.44 & 0.51 & 0.17 & -0.17 & -0.31 & 0.10 & -0.01 & -0.01 & 0.12 & -0.41 & -0.22 & -0.20 & 0.12 & 0.29 & -1.00 \\
\hline CLP & 0.582 & 0.37 & 1 & 0.38 & 0.33 & 0.33 & -0.20 & -0.43 & -0.04 & -0.11 & -0.05 & 0.32 & -0.24 & -0.27 & -0.23 & 0.15 & 0.13 & 1.00 \\
\hline BRL & 0.459 & 0.44 & 0.38 & 1 & 0.46 & 0.21 & -0.23 & -0.28 & -0.07 & -0.03 & 0.05 & -0.02 & -0.26 & -0.16 & -0.12 & 0.25 & 0.27 & 0.13 \\
\hline CDS 10 Años & 0.576 & 0.51 & 0.33 & 0.46 & 1 & 0.12 & -0.36 & -0.37 & -0.18 & 0.03 & 0.04 & -0.60 & -0.44 & -0.44 & -0.41 & 0.40 & 0.13 & 0.89 \\
\hline DXY & 0.179 & 0.17 & 0.33 & 0.21 & 0.12 & 1 & -0.08 & -0.11 & 0.15 & -0.05 & 0.05 & -0.36 & -0.24 & -0.06 & -0.04 & -0.03 & 0.45 & -0.11 \\
\hline COLCAP & -0.32 & -0.17 & -0.20 & -0.23 & -0.36 & -0.08 & 1 & 0.31 & 0.16 & -0.06 & 0.02 & 0.29 & 0.15 & 0.38 & 0.37 & -0.20 & 0.02 & 0.54 \\
\hline MXEF & -0.404 & -0.31 & -0.43 & -0.28 & -0.37 & -0.11 & 0.31 & 1 & -0.04 & 0.05 & 0.07 & 0.58 & 0.16 & 0.16 & 0.16 & -0.20 & -0.03 & -0.91 \\
\hline HEES & -0.161 & 0.10 & -0.04 & -0.07 & -0.18 & 0.15 & 0.16 & -0.04 & 1 & -0.08 & -0.02 & 0.02 & 0.04 & 0.27 & 0.27 & -0.40 & 0.24 & 0.30 \\
\hline Tasa Intervención & -0.006 & -0.01 & -0.11 & -0.03 & 0.03 & -0.05 & -0.06 & 0.05 & -0.08 & 1 & -0.01 & -0.10 & -0.09 & -0.08 & -0.06 & 0.00 & -0.01 & -0.91 \\
\hline IBR & -0.016 & -0.01 & -0.05 & 0.05 & 0.04 & 0.05 & 0.02 & 0.07 & -0.02 & -0.01 & 1 & -0.33 & -0.06 & 0.00 & 0.05 & 0.00 & 0.10 & -0.99 \\
\hline IPC Anual & -0.206 & 0.12 & 0.32 & -0.02 & -0.60 & -0.36 & 0.29 & 0.58 & 0.02 & -0.10 & -0.33 & 1 & 0.16 & -0.14 & -0.04 & -0.50 & -0.34 & -0.55 \\
\hline TES 2024 & -0.461 & -0.41 & -0.24 & -0.26 & -0.44 & -0.24 & 0.15 & 0.16 & 0.04 & -0.09 & -0.06 & 0.16 & 1 & 0.18 & 0.11 & -0.19 & -0.35 & -0.88 \\
\hline WTI & -0.44 & -0.22 & -0.27 & -0.16 & -0.44 & -0.06 & 0.38 & 0.16 & 0.27 & -0.08 & 0.00 & -0.14 & 0.18 & 1 & 0.96 & -0.18 & 0.06 & -0.36 \\
\hline BRENT & -0.411 & -0.20 & -0.23 & -0.12 & -0.41 & -0.04 & 0.37 & 0.16 & 0.27 & -0.06 & 0.05 & -0.04 & 0.11 & 0.96 & 1 & -0.16 & 0.13 & -0.19 \\
\hline VIX & 0.272 & 0.12 & 0.15 & 0.25 & 0.40 & -0.03 & -0.20 & -0.20 & -0.40 & 0.00 & 0.00 & -0.50 & -0.19 & -0.18 & -0.16 & 1 & -0.05 & 0.81 \\
\hline TESOROS 10 Años & 0.101 & 0.29 & 0.13 & 0.27 & 0.13 & 0.45 & 0.02 & -0.03 & 0.24 & -0.01 & 0.10 & -0.34 & -0.35 & 0.06 & 0.13 & -0.05 & 1 & 0.09 \\
\hline PIB Trimestral & 0.708 & -1.00 & 1.00 & 0.13 & 0.89 & -0.11 & 0.54 & -0.91 & 0.30 & -0.91 & -0.99 & -0.55 & -0.88 & -0.36 & -0.19 & 0.81 & 0.09 & 1 \\
\hline
\end{tabular}

Fuente: Elaboración propia con datos de Bloomberg (2017).

En esta investigación se realizó un análisis de las principales variables que influyen en la determinación de la tasa de cambio colombiana, tales como los flujos de capitales, la política monetaria internacional y local, el rebalanceo de índices bursátiles donde Colombia tenga alguna participación, las variables macroeconómicas como crecimiento, balanza comercial, IPC (Índice de Precios al Consumo), tasa de interés y variables cualitativas como cambios de gobierno, reuniones de bancos centrales, acuerdos de OPEP (Organización de Países Exportadores de Petróleo) y movimientos en las calificaciones de deuda soberana. En el Anexo 1 se presenta el resumen de las diferentes variables.

En la Tabla 1 se realizó una validación de algunas correlaciones promedio para el último año. En ésta se evidencian niveles fuertes de correlación en algunas variables. Sin embargo, la prima de riesgo país desde el CDS a 10 años, el índice DXY y las principales divisas de la región como el real y el peso mexicano, se destacan como las variables con mayor índice de correlación con el comportamiento de la tasa de cambio en Colombia.

Adicionalmente, en las correlaciones analizadas en la Tabla 1, se evidencia una correlación negativa fuerte del USD/COP frente al Índice de la Bolsa de Valores de Colombia (Colcap), el cual agrupa el comportamiento de los principales 20 emisores locales, entre los que 
se encuentran Bancolombia S.A., ISA S.A. Ecopetrol S.A., Grupo Sura S.A. Grupos Argos S.A. Grupo Aval S.A., entre otros. Estos emisores tienen presencia internacional y son vulnerables al contexto global, debido a que son objetivo de inversionistas extranjeros e índices bursátiles. Así, un escenario positivo en el mercado accionario anticipa flujos de dólares para la compra de activos locales, por lo cual dicha correlación es negativa.

Gráfico 3. Comportamiento de la tasa de cambio en Colombia con el Brent y WTI.

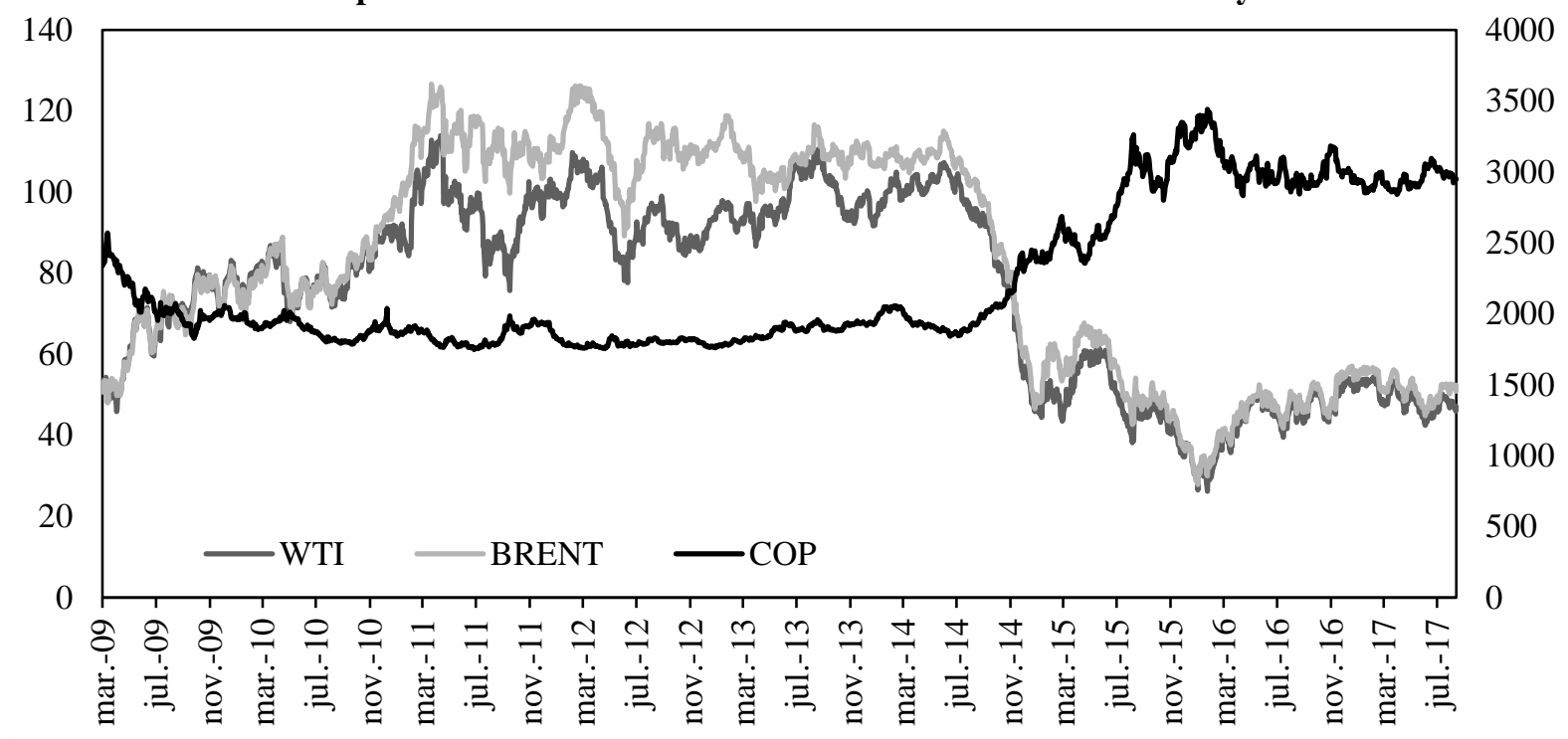

Fuente: Elaboración propia con datos de Bloomberg (2017).

A su vez, en el Gráfico 1 se observa la correlación entre los precios de cierre del USD/COP versus el petróleo posterior la apertura económica en Colombia, donde es notable la importancia del crudo para el país dada la indexación de los ingresos por la actividad petrolera, en especial la referencia Brent ${ }^{3}$, la cual es la base de negociación del agente más importante en Colombia (Ecopetrol S.A) y el precio del WTI que es la principal referencia en el mundo. Se puede apreciar que el precio del crudo tiene una correlación inversa con la tasa de cambio y la respuesta de ésta ante movimientos del crudo ha sido rápida, con una magnitud más pronunciada.

Desde el análisis realizado se permite concluir que las variables pueden tener una importancia dinámica en el tiempo y algunos autores (Rime, Sarno, \& Sojli, 2010) han llegado a la conclusión de que las variables macroeconómicas no son un buen estimador de la tasa de cambio pero, por lo contrario, sí es la tasa de cambio un estimador eficiente de las variables macroeconómicas. Esta condición le da sentido a la aplicación del modelo DCC para validar la correlación de las variables en el tiempo.

\subsection{Algunos métodos de modelación y pronóstico.}

La teoría de los regímenes cambiarios y su comportamiento ha sido objeto de estudio (como lo compilan Marsh y Sarno, 2012) en el Handbook of Exchange Rates y se ha visto el continuo surgimiento de diversas metodologías para tratar de pronosticar el comportamiento de éste. De esta manera, el análisis fundamental y los modelos monetarios en diferentes modalidades, no

\footnotetext{
${ }^{3}$ Brent crude o London Brent, su nombre se origina en la investigación petrolífera a la región del Mar del Norte de UK por Exxon Mobil y Royal Ducth Shell en el campo Shell UK Exploration con referencia al Ganso Brent, adicionalmente es acrónimo de importantes Abogados de la industria petrolera Broom, Rannoch, Etive, Ness and Tarbert. Brent contiene 0,37\% de azufre por lo cual se categoriza como dulce (One Financial Markets \& CB Financial Services Ltd, 2012).
} 
han logrado explicar satisfactoriamente el comportamiento volátil del tipo de cambio en el corto plazo, debido a que para esta temporalidad se encuentra determinado por fuerzas de oferta y demanda, que se ven influencias por múltiples factores. Por su parte, el comportamiento a medio y largo plazo, en contraste, sí permite la aplicación de modelos monetarios donde se puede analizar mediante el estudio de las variables macroeconómicas como la oferta monetaria, el PIB (Producto Interno Bruto), las tasas de interés, inflación, cuenta corriente, déficit fiscal, expectativas de los agentes en términos de liquidez, entre otras (Ordoñez, 2016).

Los modelos monetarios buscan determinar el tipo de cambio nominal y real en el largo plazo, tal como el modelo de paridad de poder adquisitivo (PPP por sus siglas en inglés purchasing power parity), desde Cassel (1922) donde a partir de los agregados monetarios se determina el valor relativo de la paridad frente a otras monedas. Por su parte, el modelo de Samuelson (1965) expone que los diferenciales de tasas de interés entre países van a predecir las variaciones del tipo de cambio y, por lo tanto, no seguirán un camino aleatorio. En la misma línea, autores como Meese y Rogoff (1983) y Taylor (2009) concluyen que a partir de los modelos estructurales se obtienen pronósticos de largo plazo mejores que los de caminata aleatoria. Sin embargo, para algunos horizontes de tiempo reconocen que el modelo de caminata aleatoria tiene un mejor desempeño considerando la media de los errores. En el mercado bursátil el modelo de caminata aleatoria ha sido abanderado por el autor Malkiel (2015), como un modelo que permite aprovechar las oportunidades del mercado.

La teoría PPP ha sido caso de estudio para diferentes autores tras la conferencia de Bretton Woods que dio lugar a la libre convertibilidad de unas monedas por otras. Por ejemplo para el análisis internacional diferentes autores (Frenkel \& Mussa, 1985; Zalduendo, 2006; Kim, Kim \& Oh, 2009; MacDonald \& Marsh, 1997) analizaron el diferencial de tasas de interés reales teniendo en cuenta las variables macroeconómicas. Por su parte, Stein y Allen (1997) consideraron el diferencial de tasas nominales de interés para el corto y el largo plazo y Edwards y Savastano (1999) realizaron una compilación bibliográfica de los estudios más representativos en términos de estudio de los determinantes de la tasa de cambio de equilibrio en el largo plazo.

Autores como Echavarría, Misas y López (2007) apuestan por la modelación de la tasa de equilibrio desde el modelo estructural de corrección de errores SVEC (por su sigla en inglés de Structural Vector Error Correction Model). El modelo SVEC es, en esencia, un modelo VAR estructural (vector autorregresivo) que considera la cointegración entre las variables que lo conforman. En este análisis encontraron una relación de cointegración entre la tasa real de cambio y sus variables macroeconómicas: los activos externos netos, los términos de intercambio y la apertura comercial. Adicionalmente Echavarría, Vásquez y Villamizar (2005) realizaron una clasificación de los modelos para tasa de cambio de equilibrio donde los principales autores fueron MacDonald y Marsh (1997).

Para el caso colombiano, Murcia y Rojas (2015) utilizan en sus modelos la variable Order Flows para explicar el comportamiento del peso colombiano en el corto plazo, y la construyen como la diferencia entre los sumatorios del valor de órdenes de compra (cotizaciones del bid) y las órdenes de venta (cotizaciones del ask) en cada intervalo de tiempo. En su artículo concluyen que los determinantes responderían principalmente a efectos de microestructura de mercado, solo para el corto plazo, dado que en trayectorias mayores obedecen a variables macroeconómicas. Otros autores se han preocupado por generar modelos partir de la microestructura de mercado y modelos tradicionales bajo fundamentales macroeconómicos; entre los más relevantes se encuentran Evans (2010) y Engel y West (2005), pero se puede concluir que los autores no hallan una conexión persistente de las variables macroeconómicas con la tasa de cambio. Adicionalmente, uno de los hallazgos más importantes para la modelación de la tasa de cambio a nivel internacional fue concluido por Engel y West (2005), quienes después de hacer un análisis compilatorio de los modelos de tipo de cambio como el 
modelo simple de mercados eficientes de Samuelson (1965), entre otros, concluyen que la tasa de cambio se ajusta a una caminata aleatoria.

Quizás uno de los principales problemas de los modelos multivariados para series financieras consiste en que los activos financieros cambian rápidamente de fuentes de volatilidad, es decir, la correlación entre los activos cambia en el tiempo. Por esta razón, algunos autores (Reboredo, 2012; Wu, Chung, \& Chang, 2012) se han preocupado por este efecto de correlación dinámica y han realizado estudios a partir de los modelos DCC. Es así como Reboredo (2012) demuestra que la importancia de los precios del petróleo con los movimientos de la tasa de cambio para el periodo de análisis (2000-2010) es débil; sin embargo después de la crisis se evidencia una mayor relación, que se magnifica dependiendo del tipo de economía, es decir, si es importadora o exportadora del crudo. Otros autores como Wu et al., (2012) evalúan también los co-movimientos de los rendimientos del precio del crudo con el dólar y concluyen que los modelos DCC que parten de los modelos GARCH presentan mejores desempeños que los modelos con CCC (Correlación Condicional Constante).

Por su parte, desde la introducción de los modelos autorregresivos ARIMA por Box y Jenkins (1970), que a pesar de ser univariados resultan convenientes para la realización de pronósticos de series de tiempo, en especial para el tipo de cambio por tratarse de modelos lineales paramétricos, tal y como lo demuestran varios autores (Lothian \& Taylor, 1996; Babu \& Reddy, 2015; Anggraeni, Vinarti y Kurniawati, 2015; Peter \& Silvia, 2012, entre otros).

Los modelos ARIMA son comúnmente utilizados como benchmark para evaluar otros métodos de pronósticos como las redes neuronales. Kamruzzaman y Sarker (2003) comparan los modelos ARIMA con los modelos ANN (por sus siglas en inglés Artificial Neural Network) dada su calidad de ajuste al dólar australiano frente a varias monedas y se concluye un mejor desempeño por parte de los modelos multivariados ANNs. En la misma línea de estudio dentro de los modelos ANNs, autores como Fahimifard, Homayounifar, Sabouhi y Moghaddamnia (2009), Gioqinang y Hu (1998) en sus artículos para el pronóstico de las paridades Iran Rial/Euro e Iran Rial/Dólar y Libra/Dólar, respectivamente resaltan que en periodos cortos los pronósticos bajos ANNs presentan mejor ajuste. De igual forma, Velásquez y González (2006) en su artículo los residuales obtenidos del modelo ANNs son menores en magnitud con relación a un modelo lineal que utiliza los mismos regresores para el índice del tipo de cambio colombiano.

De la mano de los modelos autorregresivos de medias móviles y como respuesta a las debilidades que generan los supuestos de los modelos ARIMA al suponer una varianza homecedastica, la familia de modelos ARCH ocupa también un lugar muy importante para el pronóstico de series de tiempo financieras en su segundo momento (varianza) y es un complemento a la aplicación de los modelos ARIMA para la modelación del primer momento (media). Para el caso colombiano, Uribe, Jiménez y Fernández (2015), utilizan los modelos ARCH con cambios de régimen (SWARCH), encontrando que en Colombia el tipo de cambio responde más a los flujos internaciones de capital que a las intervenciones en política monetaria, constituyéndose así la caminata aleatoria como el mejor estimador. Otros autores como Ordoñez (2016), realizaron la modelación de la volatilidad por medio de modelos ARIMA con la asociación de choques aleatorios y modelo de la volatilidad por medio de los modelos GARCH con el objetivo de capturar la heterocedasticidad de la serie de tiempo.

La tendencia de los agentes del mercado para la predicción de activos financieros ha dejado de ser tan estructural para pasar a técnicas mucho más eficientes para la toma de decisiones y en las que muchos estudios comparativos han demostrado el resultado de aplicar metodologías como el análisis técnico para la predicción. Lo que tiene buenos resultados generalmente para los portafolios de inversión, buscando patrones de comportamiento predecibles en las series de precios y de volúmenes de negociación. La referenciación de estudios en materia de análisis técnico y redes neuronales es amplia y autores como González 
(2003), Parisi, Parisi y Cañas (2002), Fernández, González y Sosvilla (2000) y FernándezRodríguez, Sosvilla-Rivero y Andrada-Félix (1999) demuestran que este tipo de metodologías tienen relevancia en el mercado bursátil.

En el próximo apartado se presentarán los modelos autorregresivos ARIMA, ARIMAX, la familia de modelos ARCH y el modelo DCC para posteriormente presentar la aplicación y análisis para el tipo de cambio peso frente al dólar.

\section{Metodología.}

\subsection{Modelo Autorregresivo Integrado de Medias Móviles (ARIMA).}

El comportamiento de la mayoría de series financieras están explicadas como caminatas aleatorias y en especial al tasa de cambio, como lo demuestran Meese y Rogoff (1983). Para su pronóstico es común aplicar metodólogas de modelación de series de tiempo como el modelo “autorregresivo integrado en media móvil” ARIMA, el cual fue introducido por Box y Jenkins (1970). El proceso general parte de dos componentes: el componente AR es la serie rezagada en sí misma, y el componente MA son los rezagos en término de error originados por el carácter estocástico de los modelos ARMA. Es decir, los términos autorregresivos para una variable dependiente son sus valores rezagados que tienen una relación estadísticamente significativa con su valor más reciente y, por su parte lo,s términos de medias móviles son residuos o errores rezagados de las estimaciones realizadas.

Un proceso general ARMA $(p, q)$ con $p$ términos autorregresivos y $q$ términos de promedio móviles:

$$
Y_{t}=\delta+\phi_{1} Y_{t-1}+\phi_{2} Y_{t-2}+\cdots+\phi_{p} Y_{t-p}+\theta_{1} \varepsilon_{t-1}+\theta_{2} \varepsilon_{t-2}+\cdots+\theta_{q} \varepsilon_{t-q}
$$

Sea $Y_{t}$ un proceso estocástico no estacionario pero que al diferenciarlo $d$-veces, se transforma en estacionario en media, y se dice que $Y_{t}$ sigue un proceso ARIMA $(p, d, q)$ si la $d$ - ésima diferencia de $Y_{t}$ sigue un proceso estacionario ARMA $(p, q)$.

$$
\text { Sea } W_{t}=(1-L)^{d} Y_{t} \text {, }
$$

Como $W_{t}$ es un proceso estacionario en media, se puede modelar bajo la estructura ARMA. Bajo la notación del operador de rezagos:

$$
\left(1-\phi_{1} L-\phi_{2} L^{2}-\cdots-\phi_{P} L^{P}\right) W_{t}=\left(1-\theta_{1} L-\theta_{2} L^{2}-\cdots-\theta_{q} L^{q}\right) \varepsilon_{t},
$$

Sustituyendo ecuación (2) en ecuación (3):

$$
\left(1-\phi_{1} L-\phi_{2} L^{2}-\cdots-\phi_{P} L^{P}\right)(1-B)^{d} Y_{t}=\left(1-\theta_{1} L-\theta_{2} L^{2}-\cdots-\theta_{q} L^{q}\right) \varepsilon_{t}
$$

Se obtiene

$$
\phi(L)(1-L)^{d} Y_{t}=\theta_{0}+\theta(L) \varepsilon_{t},
$$

Lo cual corresponde al modelo ARIMA $(p, d, q)$, notación algebraica:

$$
\Delta y_{t}=\theta_{0}+\phi_{1} y_{t-1}+\phi_{2} y_{t-2}+\cdots+\phi_{p} y_{t-p}+\theta_{1} \varepsilon_{t-1}+\theta_{2} \varepsilon_{t-2}+\cdots+\theta_{q} \varepsilon_{t-q},
$$

donde:

$\phi(L)=1-\phi_{1} L-\phi_{2} L^{2}-\cdots-\phi_{P} L^{P}$; es el operador AR estacionario 
$\theta(L)=1-\theta_{1} L-\theta_{2} L^{2}-\cdots-\theta_{q} L^{q} ;$ es el operador MA invertible.

No existen factores comunes entre $\phi(L)$ y $\theta(L)$ y $\varepsilon_{t}$ es un proceso de ruido blanco de media cero.

El parámetro $\theta_{0}$ juega papeles muy distintos cuando $d=0$ y cuando $d>0$. En el caso de tener $d=0$, el proceso original $Y_{t}$ es estacionario y $\theta_{0}$ está relacionado con la media del proceso original:

$$
\theta_{0}=\varepsilon \phi(1)=\varepsilon\left(1-\phi_{1}-\phi_{2}-\cdots-\phi_{p}\right),
$$

Cuando $d>0, \theta_{0}$ corresponde al coeficiente $t^{d}$ de una tendencia determinística de orden d. $\theta_{0}$ Es llamado deriva y debe ser incluido en el modelo cuando realmente sea necesitado.

\subsection{Modelo Autorregresivo Integrado de Medias Móviles con Variable Exógena (ARIMAX).}

El modelo ARIMAX es una extensión del modelo ARIMA y el desempeño de ambos modelos ha sido caso de estudio por diferentes autores que se han preocupado por comparar ambos modelos (Andrews \& Dean, 2013; Pektaş \& Kerem Cigizoglu, 2013; Anggraeni et al., 2015). En ocasiones no es suficiente con los términos de AR y MA en un modelo ARIMA para pronosticar la variable, por lo que se hace necesario incorporar al modelo una variable independiente que le permita capturar la influencia de los choques externos a la variable dependiente. Este tipo de modelos han tomado gran relevancia para activos con sensibilidad a choques externos por cambios en las variables macroeconómicas y financieras, con niveles de correlación significativos para el periodo de análisis.

La denotación para un proceso general con términos autorregresivos, nivel de diferencias, términos de promedios móviles y variables explicativas sería:

$\Delta y_{t}=\varepsilon_{t}+\delta+\beta_{1} x_{1}+\cdots+\beta_{n} x_{n}+\phi_{1} y_{t-1}+\cdots+\phi_{p} y_{t-p}+\theta_{1} \varepsilon_{t-1}+\cdots+\theta_{q} \varepsilon_{t-q}$,

Existen cuatro supuestos estadísticos que se deben examinar para asegurar que los resultados del modelo ARIMAX sean válidos:

1. Las series de tiempo correspondientes a las variables y deben ser estacionarias, es decir, cuando es estable y tanto la media como la varianza no son constantes en el tiempo.

2. Los residuos no deben poseer un nivel significativo de autocorrelación. En el caso de dependencia lineal de los residuos se debe calibrar el modelo por medio de los procesos AR y/o MA. Se evalúa mediante el test de Breush-Godfrey o Durbin-Watson - Q de LjungBox.

3. El valor-p de las variables exógenas debe ser significativo para que éstas puedan estar incluidas dentro del modelo, por lo tanto, si el coeficiente es significativo los residuos de la regresión sean ruido blanco.

4. La variable exógena puede mostrar o no una relación significativa con la variable dependiente. Sin embargo, la variable dependiente no debería explicar las variables exógenas. Con el objetivo de verificar el cumplimiento del supuesto se aplicara el Test de causalidad de Granger ${ }^{4}$ (Chong \& Aguilar, 2016); si la variable exógena posee un nivel significativo de causalidad debe ser retirada del modelo para evitar multicolinealidad.

\footnotetext{
${ }^{4}$ Test de causalidad de Granger para identificar causalidad de las variables (Granger, 1986).
} 


\subsection{Familia de Modelos de Heterocedasticidad Condicional Autorregresiva ARCH.}

Las series financieras son modeladas generalmente a partir de los retornos de las mismas, los cuales capturan los movimientos de las variables que son irregulares. Sin embargo, los modelos econométricos realizan fuertes supuestos sobre la volatilidad de las series suponiéndola constante en el tiempo; sin embargo la mayoría de series financieras presentan periodos inusuales de volatilidad (Clusters ${ }^{5}$ ), como lo trata Mandelbrot (1963) tienden a tener exceso de curtosis (leptocurticas), con colas más pesadas que la distribución normal; esta condición invalida el supuesto de homocedasticidad.

Los modelos ARHC fueron introducidos por Engle (1982) con el objetivo de capturar algunos de los hechos estilizados o en otros términos la heterocedasticidad de las variables. El modelo ARCH de orden $p$, tiene la siguiente estructura:

$$
\sigma_{t}^{2}=\delta_{0}+\delta_{1} \varepsilon_{t-1}^{2}+\delta_{2} \varepsilon_{t-2}^{2}+\cdots+\delta_{p} \varepsilon_{t-p}^{2},
$$

donde el Coeficiente $\delta_{0}$ tal que $\delta_{0}>0$ y $\delta_{i}$ tal que $0 \leq \delta_{i}>1$, para $i=1,2, \ldots, p$.

En términos del operador de rezagos el modelo general ARCH se puede expresar como,

$$
\sigma_{t}^{2}=\delta_{0}+\delta(L) \varepsilon_{t}^{2}
$$

donde $\delta(\mathrm{L})=\delta_{0}+\delta_{1}(\mathrm{~L})+\cdots+\delta_{p}(L)^{p}$

El modelo ARCH asume que los choques negativos y positivos tienen el mismo efecto sobre la volatilidad, debido a que ella depende del cuadrado de los rezagos de las perturbaciones y genera supuesto de normalidad para garantizar que la varianza sea positiva, por lo cual nacen otros modelos de volatilidad condicional heteroscedástica que explican la dinámica de $\sigma_{\mathrm{t}}^{2} \mathrm{y}$ cómo evoluciona en el tiempo. Entre ellos se encuentran los modelos GARCH con asimetría, el cual permite una especificación más parsimoniosa para la función de la varianza condicional, eliminando el supuesto de normalidad e incorporando la realidad de la mayoría de series financieras que cumplen con la característica de colas pesadas y clusters de volatilidad. El modelo GARCH tiene una estructura más flexible al incorporar rezagos de la varianza condicional. El modelo GARCH $(s, m)$ tiene la siguiente estructura algebraica:

$$
\begin{gathered}
\varepsilon_{t}=r_{t}-\mu_{t}=z_{t} \sigma_{t} \\
\sigma_{t}^{2}=\alpha_{0}+\sum_{j=1}^{s} \beta_{j} \sigma_{t-j}^{2}+\sum_{i=1}^{m} \alpha_{i} \varepsilon_{t-i}^{2}= \\
\sigma_{t}^{2}=\alpha_{0}+\beta_{1} \sigma_{t-1}^{2}+\cdots+\beta_{s} \sigma_{t-s}^{2}+\alpha_{1} \varepsilon_{t-1}^{2}+\cdots+\alpha_{m} \varepsilon_{t-m}^{2},
\end{gathered}
$$

donde $z_{t}$ es una serie de variables aleatorias i.i.d (independientes e idénticamente distribuidas) con media cero y varianza 1 , con $\alpha_{i} \geq 0$ para $i=1, \ldots, m$ y $\beta_{j} \geq 0$ para $j=$ $1, \ldots, s$, el cumplimento de estos supuestos garantizan que la varianza sea no negativa.

En términos del operador de rezagos,

$$
\beta(L) \sigma_{t}^{2}=\alpha_{0}+\alpha(L) \varepsilon_{t}^{2}
$$

donde $\alpha(L)=\alpha_{1}(L)+\cdots+\alpha_{m}(L)^{m}$ y $\beta(L)=1-\beta_{1}-\cdots-\beta_{S}(L)^{S}$

\footnotetext{
${ }^{5}$ Grandes (pequeños) cambios en la variable retorno tienden a ser seguidos por grandes (pequeños) cambios de cualquier signo.
} 
Otros modelos de la Familia ARCH son por ejemplo EGARCH (GARCH exponencial), APARCH (ARCH con potencia asimétrica), SWGARCH y modelos de umbral TARCH entre otros. Uribe et al. (2015) y Ordoñez (2016) hicieron usó de los modelos SWARCH y GARCH para modelar al volatilidad de la tasa de cambio en Colombia.

\subsection{Modelo de correlación dinámica condicional (DCC)}

Engle (2002) desarrolló los modelos ARCH e introdujo a su vez el modelo de correlación dinámica condicional, el cual sugiere una medida de correlación dinámica en el tiempo entre una variable endógena y un grupo de variables exógenas. Este tipo de modelos ha sido utilizado en el análisis de cambios de correlación durante periodos de crisis en Europa y Asia por diferentes autores (Syllignakis \& Kouretas, 2011; Serwa \& Bohl, 2005; Chiang, Jeon, \& Li, 2007) que encontraron que en periodos de crisis, dado el aumento de la correlación de los activos del mercado bursátil con las variables macroeconómicas y el nivel de tipo de cambio, generan un efecto de contagio financiero.

El modelo DCC parte de un GARCH multivariado donde los números de parámetros son independientes al número de series utilizadas y por eso también son llamados modelos DCCGARCH. Sea $w_{t}$ un proceso estocástico donde $M$ es una matriz de correlaciones condicionales y $D_{t}$ es una matriz diagonal con la siguiente forma:

$$
\begin{gathered}
W_{t}=D_{t} M_{t} D_{t} . \\
D_{t}=\left[\begin{array}{ccc}
\sigma_{1, t}^{2} & 0 & 0 \\
0 & \sigma_{2, t}^{2} & 0 \\
0 & 0 & \sigma_{3, t}^{2}
\end{array}\right] .
\end{gathered}
$$

donde $\sigma_{i, t}^{2}$ se estima a través de un modelo GARCH multivariado de la siguiente forma:

$$
\sigma_{i, t}^{2}=\alpha_{i}+\sum_{j=1}^{p_{i}} \alpha_{j} \epsilon_{i, t-j}^{2}+\sum_{j=1}^{q_{i}} \beta_{j} \sigma_{i, t-j}^{2}+\sum_{j=1}^{n_{i}} \gamma_{j} \epsilon_{i, t-j}^{2}
$$

Siendo:

$\sigma_{i, t}^{2}$ Varianza condicional de la serie.

$a_{i}$ Valor constante de la estimación.

$\beta_{j}$ Término constante que mide la persistencia de la volatilidad.

$\alpha_{j}$ Término constante que mide los efectos ARCH.

$\gamma_{j}$ Término constante que mide la asimetría de la varianza.

Bajo la condición de que $\alpha_{j}>0, \alpha_{j}+\beta_{j}<1$, una vez obtenido los parámetros $a_{i}, \beta_{j} y \alpha_{j}$, se calculan las correlaciones las correlaciones dinámicas de la siguiente manera:

$$
\begin{gathered}
E_{t-1}\left(\epsilon_{t} \epsilon_{t}^{\prime}\right)=D_{t}^{-1} W_{t} D_{t}^{-1}=M_{t}, \\
\rho_{i, j, t}=\frac{q_{i, j, t}}{\sqrt{q_{i, i, t} q_{j, j, t}}}
\end{gathered}
$$

Luego se obtiene la matriz de correlaciones $W_{t}$ :

$$
W_{t}=\left[\begin{array}{ccc}
1 & \rho_{1,2, t} & \rho_{1,3, t} \\
\rho_{2,1, t} & 1 & \rho_{2,3, t} \\
\rho_{3,1, t} & \rho_{3,2, t} & 1
\end{array}\right] \text {, }
$$




\section{Método de estimación, datos y resultados.}

\subsection{Análisis exploratorio de los datos.}

Se propone un análisis de carácter exploratorio en el que se busca determinar el modelo con mejor ajuste de corto plazo para la tasa de cambio en Colombia por medio de los retornos diarios de los precios de cierre USD/COP, dado que estos precios presentan valores de correlación más altos con las variables explicativas. Adicionalmente, se modela la serie de tipo de cambio bajo la misma base de último precio y no sobre un promedio ponderado como lo es la TRM (Tasa Representativa del Mercado ${ }^{6}$ ) que puede tener un sesgo frente a los hechos de cierre por su metodología de cálculo.

Inicialmente se realizó un análisis de co-movimientos entre los retornos diarios del tipo de cambio y las series Índice DXY, Índice Colcap, CDS 10 años Colombia, Índice IBR, Tesoros con vencimiento 10 años, índice MXEF, WTI, TES con vencimiento 2024, índice VIX, USD/CLP y USD/MXN en el periodo que comprende desde el 3 de enero de 2011 hasta el 15 de mayo de 2017 para un total de 1661 observaciones.

En el modelo ARIMAX-GARCH se utilizó información histórica para las diferentes variables analizadas a partir del DCC. Sin embargo, en la calibración del modelo ARIMAXGARCH fueron significativas las siguientes variables exógenas para la explicación del USD/COP: los TES vencimiento julio 2024, el Índice DXY y el precio del petróleo por medio de la referencia WTI. Adicionalmente, se realizó la incorporación de una variable Dummy ${ }^{7}$ (D1) tanto en el Modelo ARIMA como en el Modelo ARIMAX con el objeto de capturar valores atípicos por choques exógenos de gran impacto que no son recurrentes, tales como las reuniones más relevantes $\mathrm{OPEC}^{8}$ del 24 al 31 de agosto de 2015 y el 8 de diciembre de 2015, pues se considera que estas dos reuniones generaron mucha incertidumbre en el mercado cambiario colombiano, al ser el petróleo la principal exportación colombiana.

Los valores missing correspondientes a periodos no operativos en uno u otro mercado debidos a festivos fueron reemplazados por el dato inmediatamente anterior para obtener semanas de cinco días. La elección de los datos se hizo con base en información de mercado y análisis de correlaciones donde se evidencia mayor incidencia de los movimientos de las variables seleccionadas en el nivel la tasa de cambio en Colombia. La fuente de los datos fue la plataforma Bloomberg. Los cálculos de los Modelos ARIMA y ARIMAX se hicieron en el software econométrico R. El Gráfico 4 muestra la evolución de las series en el período seleccionado.

En la estimación de los modelos se validaron todas las variables estudiadas en el Anexo 1 que fueron analizadas bajo el modelo DCC, de las cuales fueron seleccionadas para la modelación las variables con nivel de significancia positiva, descartando las demás variables de los análisis.

La inspección visual de series de originales parece indicar no estacionariedad (ver Gráfico 4) en cada una de las series, lo que es una característica propia de las series financieras.

\footnotetext{
${ }^{6}$ En Colombia la Tasa Representativa del Mercado se conoce como TRM, que corresponde a la cantidad de pesos colombianos por dólar estadunidense y es calculada como el promedio ponderado de las operaciones de compra y venta de moneda legal colombiana contra dólar, realizadas por los Intermediarios del Mercado Cambiario (IMC) en el mercado spot (Banco de la Republica Colombia, 2017).

${ }^{7}$ La variable Dummy (D1) es una variable binaria que toma el valor de 1 durante reuniones de la OPEC y 0 en los demás días.

${ }^{8}$ Organización de Países Exportadores de Petróleo, por su denominación en ingles OPEC (Organization of the Petroleum Exporting Countries).
} 
A partir de estas series se calculó el retorno logarítmico, el cual se presenta a continuación en el Gráfico 5.

Gráfico 4. Evolución de las series diarias, periodo 2011-2017.

COP

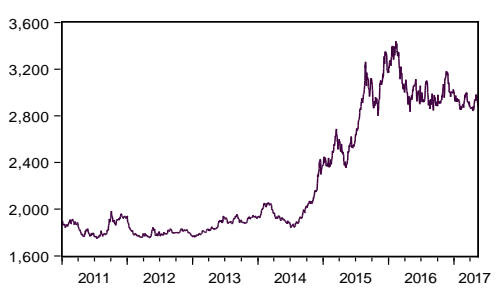

TESOROS10

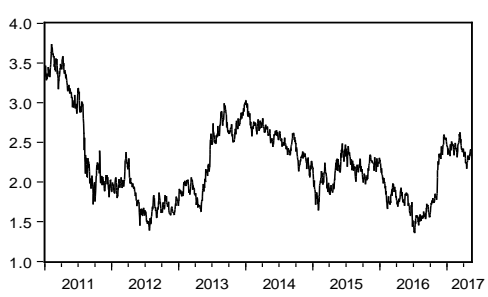

CLP
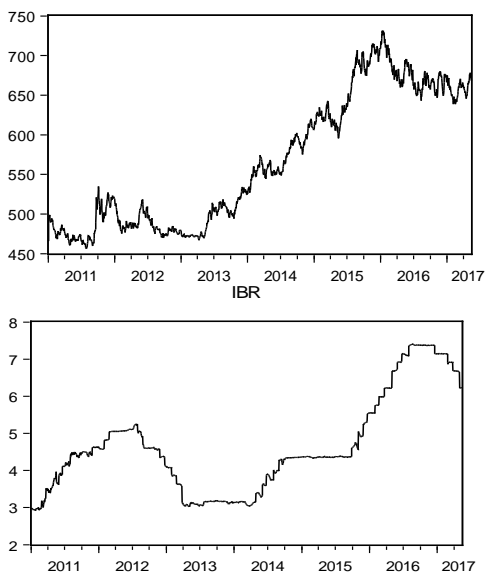

WTI

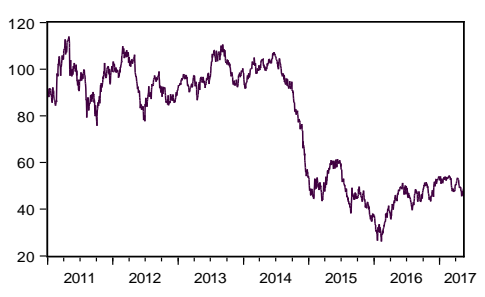

MXN

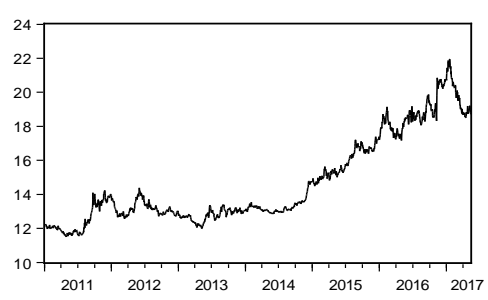

COLCAP
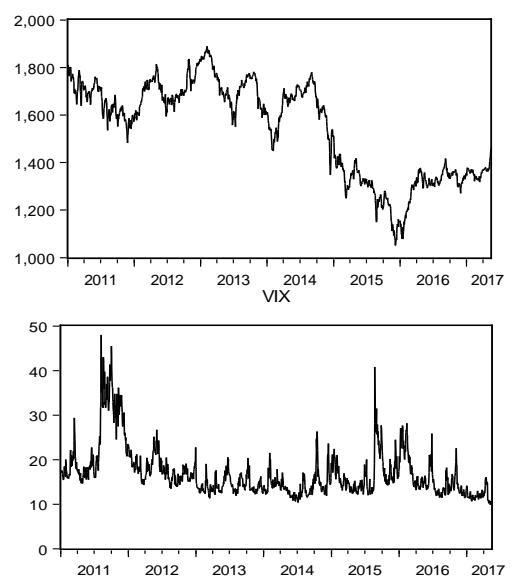

TES24

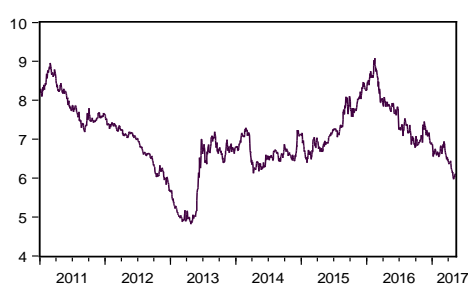

MXE

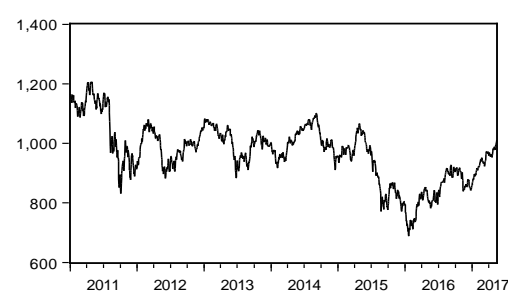

DXY
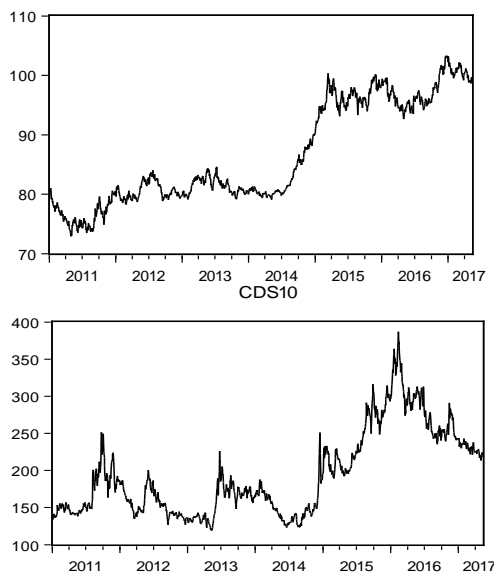

Fuente: Elaboración propia con datos de Bloomberg (2017).

Los retornos de las variables presentan volatilidad irregular que se puede identificar a través de la presencia de clusters, así como también datos atípicos que pueden originarse por choques externos de gran magnitud. Por ende, las distribuciones de las series tendrán la característica de colas pesadas.

Según la Tabla 2, el P-Valor del Jarque-Bera comprueba que las series originales no se ajustan a una distribución normal, adicionalmente el P-valor del test de Dickey Fuller no rechaza la hipótesis nula de la existencia de raíz unitaria, por esta razón ninguna de las series es estacionaria. La condición anterior hace necesario realizar la modelación sobre los retornos de las series y no sobre los valores en niveles. 
Gráfico 5. Retornos diarios periodo 2011-2017.
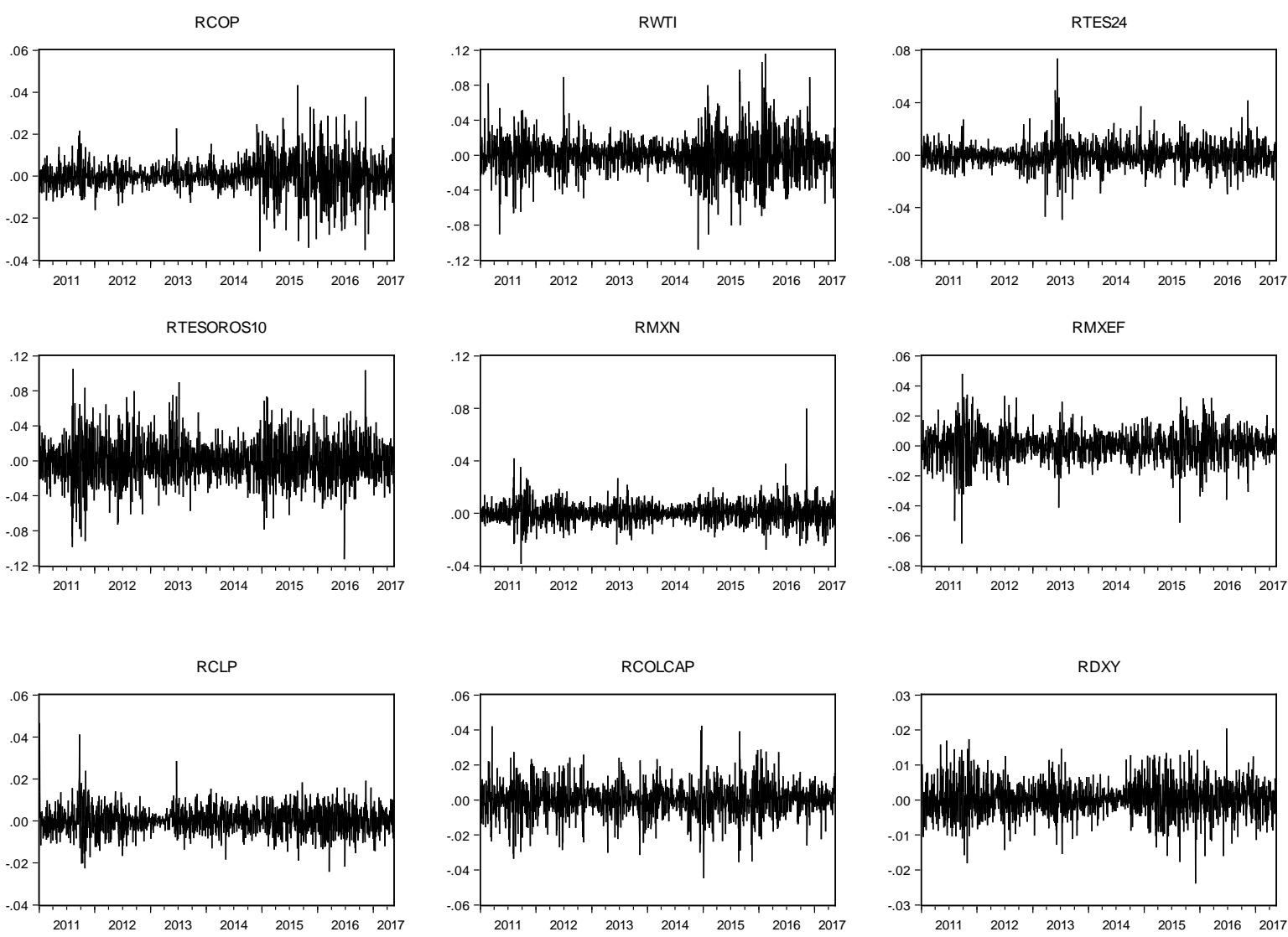

RIBR

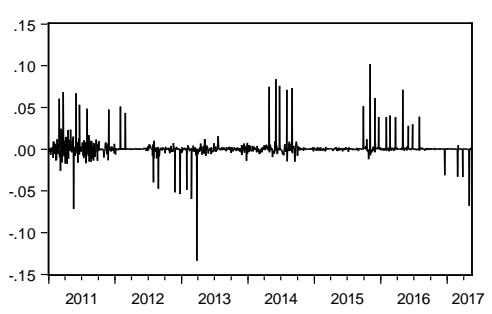

RVIX
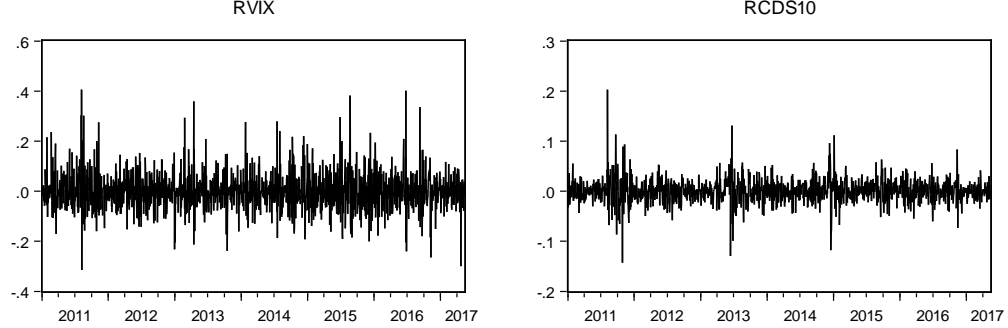

Fuente: Elaboración propia con datos de Bloomberg (2017).

Tabla 2. Estadísticos descriptivos para las series diarias originales, 2011 - 2017.

\begin{tabular}{|c|c|c|c|c|c|c|c|c|c|c|c|c|}
\hline & COP & WTI & TES24 & TESOROS10 & MXN & MXEF & CLP & COLCAP & DXY & IBR & VIX & CDS10 \\
\hline Media & $2,260.08$ & 77.14 & 7.03 & 2.24 & 14.69 & 968.35 & 566.82 & $1,541.77$ & 86.57 & 4.64 & 16.83 & 194.29 \\
\hline Mediana & 1,932.85 & 88.73 & 7.00 & 2.18 & 13.34 & 975.46 & 551.20 & 1,609.71 & 82.36 & 4.36 & 15.31 & 176.00 \\
\hline Máximo & $3,440.55$ & 113.93 & 9.08 & 3.74 & 21.96 & $1,206.49$ & 731.46 & $1,889.30$ & 103.30 & 7.40 & 48.00 & 386.69 \\
\hline Mínimo & $1,747.65$ & 26.21 & 4.82 & 1.36 & 11.50 & 688.52 & 456.38 & $1,051.25$ & 72.93 & 2.92 & 9.77 & 118.85 \\
\hline Desviación estándar & 526.06 & 24.80 & 0.84 & 0.49 & 2.61 & 98.43 & 83.57 & 199.54 & 8.69 & 1.31 & 5.54 & 57.02 \\
\hline Asimetría & 0.69 & -0.40 & -0.24 & 0.70 & 0.93 & -0.20 & 0.30 & -0.41 & 0.39 & 0.75 & 2.14 & 0.84 \\
\hline Curtosis & 1.80 & 1.52 & 3.34 & 3.04 & 2.59 & 2.92 & 1.54 & 1.89 & 1.59 & 2.60 & 8.40 & 2.77 \\
\hline P-Valor Jarque-Bera & 0.00 & 0.00 & 0.00 & 0.00 & 0.00 & 0.00 & 0.00 & 0.00 & 0.00 & 0.00 & 0.00 & 0.00 \\
\hline P-Valor Dickey Fuller & 0.89 & 0.80 & 0.39 & 0.07 & 0.87 & 0.05 & 0.81 & 0.38 & 0.83 & 0.84 & 0.03 & 0.31 \\
\hline P-Valor Ljung-Box & 0.00 & 0.00 & 0.00 & 0.00 & 0.00 & 0.00 & 0.00 & 0.00 & 0.00 & 0.00 & 0.00 & 0.00 \\
\hline
\end{tabular}

Fuente: Elaboración propia con datos de Bloomberg (2017). 
Por medio de la Tabla 3, se evidencia que las series de retornos son leptocúrticas. El retorno de la paridad USD/COP y las variables explicativas presentan asimetría positiva en la mayoría de los casos, a excepción del colcap y el índice MXEF. En todos casos se rechaza la hipótesis de normalidad y el p-valor del test de Dickey Fuller en todos los casos se rechaza la hipótesis nula de presencia de raíz unitaria en los retornos por lo cual se comprueba que dichas series son estacionarias. El p-valor del estadístico Ljung-Box rechaza la hipótesis nula de no autocorrelación, lo cual indica que hay evidencia a favor de la existencia de estructura de dependencia temporal en media, razón por la cual los modelos ARIMA son apropiados para la modelación.

Tabla 3. Estadísticos descriptivos para los retornos de las series diarias, 2011 - 2017.

\begin{tabular}{lcccccccccccc}
\hline & COP & WTI & TES24 & TESOROS10 & MXN & MXEF & CLP & COLCAP DXY & IBR & VIX & CDS10 \\
\hline \hline Media & 0.000 & 0.000 & 0.000 & 0.000 & 0.000 & 0.000 & 0.000 & 0.000 & 0.000 & 0.000 & 0.000 & 0.000 \\
Mediana & 0.000 & 0.000 & 0.000 & -0.001 & 0.000 & 0.000 & 0.000 & 0.000 & 0.000 & 0.000 & -0.002 & 0.000 \\
Máximo & 0.043 & 0.116 & 0.074 & 0.105 & 0.080 & 0.048 & 0.047 & 0.042 & 0.020 & 0.102 & 0.405 & 0.203 \\
Mínimo & -0.036 & -0.108 & -0.049 & -0.113 & -0.039 & -0.065 & -0.024 & -0.045 & -0.024 & -0.134 & -0.314 & -0.143 \\
Desviación estándar & 0.007 & 0.021 & 0.009 & 0.024 & 0.008 & 0.010 & 0.006 & 0.009 & 0.005 & 0.010 & 0.073 & 0.023 \\
Asimetría & 0.054 & 0.146 & 0.542 & 0.078 & 0.815 & -0.379 & 0.456 & -0.132 & 0.022 & 1.077 & 0.698 & 0.394 \\
Curtosis & 7.097 & 6.235 & 8.967 & 4.548 & 11.374 & 6.059 & 7.156 & 5.611 & 4.708 & 59.853 & 6.717 & 10.849 \\
P-Valor Jarque-Bera & 0.000 & 0.000 & 0.000 & 0.000 & 0.000 & 0.000 & 0.000 & 0.000 & 0.000 & 0.000 & 0.000 & 0.000 \\
P-Valor Dickey Fuller & 0.000 & 0.000 & 0.000 & 0.000 & 0.000 & 0.000 & 0.000 & 0.000 & 0.000 & 0.000 & 0.000 & 0.000 \\
P-Valor Ljung-Box & 0.000 & 0.000 & 0.000 & 0.000 & 0.000 & 0.000 & 0.000 & 0.000 & 0.000 & 0.000 & 0.000 & 0.000 \\
\hline
\end{tabular}

Fuente: Elaboración propia con datos de Bloomberg (2017).

\subsection{Aplicación del modelo ARIMA-GARCH}

La modelación de los retornos de USD/COP se realizó a partir del modelo ARIMA para la parte en media y se complementó con el modelo GARCH para la modelación en varianza con el objetivo de capturar la existencia de estructura de dependencia temporal tanto en media como en varianza.

Para la identificación del orden de la serie temporal de la estructura ARIMA se generó el correlograma de los retornos del USD/COP y se observaron los gráficos de ACF (Autocorrelación) y PACF (Correlación Parcial) (ver Anexo 2) para identificar la presencia de los componentes AR y/o MA en la serie. Se obtuvo como resultado con un nivel de significación del 5\% la presencia de estructura AR en los rezagos 1 y 9. Sin embargo, no se encontró presencia de estructura MA.

Se estimaron los modelos ARIMA $(1,1,0)$ y ARIMA $(9,1,0)$, los cuales fueron verificados bajo los criterios de selección Akaike, Schwarz, Hannan-Quinn, R-cuadrado y Durbin Watson (ver Anexo 3) y se seleccionó el modelo ARIMA $(9,1,0)$.

Los residuales del modelo ARIMA permitieron evidenciar existencia de efecto ARCH, por medio del correlograma de los cuadrados de los residuales, $\varepsilon_{t}^{2}$ (ver Anexo 4), respaldo adicionalmente por el test ARCH - LM (Test Multiplicador de Lagrange) con un p-valor para Chi-Cuadrado de Cero (0), rechazando la hipótesis nula de no existencia de efecto ARCH.

El modelo GARCH fue propuesto por Bollerslev (1986) como una extensión al modelo ARCH. Ésta es una especificación más parsimoniosa para la función de la varianza condicional con una estructura de rezago más flexible que la ofrecida por el modelo ARCH, el cual permite la inclusión de rezagos de la varianza condicional en la ecuación de varianza. 
La validación final de modelo se realizó aplicando de nuevo el análisis de los correlogramas de los residuos y los residuos al cuadrado por medio de la realización de pruebas de Ljung y Box (ver Anexo 5) donde se acepta la hipótesis nula de no autocorrelación serial de los residuos y se comprueba la remoción de la estructura de dependencia temporal en media y en varianza. También se aplicó el test de Dickey-Fuller aumentado con el cual se comprueba que los errores son ruido blanco. Adicionalmente el test ARCH - LM arrojó un p-valor para Chi-Cuadrado de Cero (0.73), con lo cual se aceptó la hipótesis nula de no existencia de efecto ARCH para los errores al cuadrado, reflejando una buena calibración del modelo.

Por lo tanto, dada la condición de heterocedasticidad condicional se procedió a estimar el modelo bajo la estructura ARCH y se obtuvo un modelo ARIMA $(9,1,0)$ - GARCH $(1,1)$ (Tabla 4).

Tabla 4. Resultados del Modelos ARIMA - GARCH.

\begin{tabular}{ccccc}
\hline \multicolumn{5}{c}{ Ecuación de la Media } \\
\hline Variable & Coeficiente & Error Estándar & Estadístico -Z & Probabilidad \\
\hline C & $8.77 E-05$ & 0.000151 & 0.581927 & 0.5606 \\
D1 & 0.006981 & 0.001523 & 4.583067 & 0 \\
AR(1) & 0.067072 & 0.024999 & 2.683049 & 0.0073 \\
AR(9) & 0.093356 & 0.026592 & 3.510645 & 0.0004 \\
\hline Variable & Coeficiente & Error Estándar & Estadístico -Z & Probabilidad \\
\hline C & $1.29 E-07$ & 0.000000 & 2.620183 & 0.0088 \\
RESID(-1)^2 & 0.058359 & 0.005895 & 9.900282 & 0.0000 \\
GARCH(-1) & 0.941879 & 0.005378 & 175.147 & 0.0000 \\
\hline \hline R-squared & 0.009248 & Mean dependent var & 0.000253 \\
Adjusted R-squared & 0.007453 & S.D. dependent var & 0.007449 \\
S.E. of regression & 0.007422 & Akaike info criterion & -7.369054 \\
Sum squared resid & 0.091213 & Schwarz criterion & -7.346222 \\
Log likelihood & 6123.315 & Hannan-Quinn criter. & -7.360592 \\
Durbin-Watson stat & 2.004227 & & \\
\hline
\end{tabular}

\section{Ecuación Media modelo ARIMA-GARCH}

$$
\begin{gathered}
\Delta U S D / C O P_{t}=8.77 E-05+0.067072 \Delta U S D / C O P_{t-1}+0.093356 \Delta U S D / C O P_{t-9}+ \\
0.006981 \mathrm{D} 1
\end{gathered}
$$

\section{Ecuación Varianza modelo ARIMA-GARCH}

$$
\sigma_{t}^{2}=1.29 \mathrm{E}-07+0.058359 \varepsilon_{t-1}^{2}+0.941879 \sigma_{t-1}^{2}
$$

El modelo presenta un coeficiente muy relevante para el rezago superior $t+9$ del 9.33\%, es decir, el rezago a nueve periodos tiene un impacto directamente proporcional y la información más actualizada del activo teniendo en cuenta que es una serie ruido blanco la aporta un 6.70\% por ende la historia del par USD/COP nos es el factor determinante del nivel de tasa de cambio, sin embargo, ambos rezagos capturan la mayor cantidad de información para la construcción de la tasa de cambio. 


\subsection{Resultados de los modelos DCC.}

Los modelos GARCH permiten eliminar grandes supuestos de otros modelos de pronóstico que no consideran los cambios de volatilidad, como el efecto de los clusters, que hacen que los choques de volatilidad sean persistentes por un tiempo, siendo una realidad inherente a la mayoría de activos financieros la probabilidad de valores atípicos que da lugar a distribuciones de colas pesadas. Es así como dada la dinámica de los activos en el tiempo, el modelo DCC que parte de la modelación de la varianza condicional de cada activo permite analizar, a su vez, la dinámica de la interacción entre las variables de estudio por medio de la correlación.

Dentro de los modelos DCC estimados se evidencia que la mayoría de las variables exógenas analizadas, incluyendo las variables significativas en el modelos ARIMAX (Ver Tabla 8) para el tipo de cambio en Colombia, la suma de los parámetros $\alpha+\beta \approx 1$ son cercanas a 1 (Tabla 5). Lo cual significa que tienen una correlación dinámica persistente en el tiempo e indica a su vez la magnitud de reversión a la media, excluyendo las variables índice IBR, índice VIX y los CDS de 10 años que la suma de los parámetros indican correlación que no hay presencia de correlación dinámica condicional.

Tabla 5. Parámetros modelo DCC.

\begin{tabular}{lccc}
\hline Pareja D.C.C. $(\boldsymbol{\rho})$ & Alpha $(\boldsymbol{\alpha})$ & Beta $(\boldsymbol{\beta})$ & $(\boldsymbol{\alpha})+(\boldsymbol{\beta})$ \\
\hline \hline USD/COP _WTI & 0.0110 & 0.9850 & 0.9960 \\
USD/COP _TES24 & 0.0190 & 0.9720 & 0.9910 \\
USD/COP _TESOROS10Y & 0.0180 & 0.9720 & 0.9900 \\
USD/COP_MXN & 0.0060 & 0.9830 & 0.9890 \\
USD/COP _MXEF & 0.0160 & 0.9700 & 0.9860 \\
USD/COP _CLP & 0.0150 & 0.9700 & 0.9850 \\
USD/COP _Colcap & 0.0240 & 0.9530 & 0.9770 \\
USD/COP _DXY & 0.0340 & 0.9240 & 0.9580 \\
USD/COP _IBR & 0.0660 & 0.5920 & 0.6580 \\
USD/COP _VIX & 0.0280 & 0.4810 & 0.5090 \\
USD/COP_CDS10 & 0.0480 & 0.0000 & 0.0480 \\
\hline
\end{tabular}

Fuente: Elaboración propia con datos de Bloomberg (2017).

Para el caso de las variables índice IBR, VIX y CDS10 se encontró que no presentan un índice de correlación dinámica significativo contra el par USD/COP. De esta manera, y como se puede observar en el Gráfico 6, las correlaciones DCC presentan estacionariedad por lo cual es preciso decir que son constantes en media y la relación de dependencia frente a la tasa de cambio es estable en el tiempo para el periodo de análisis. Adicionalmente, en la Tabla 6 se presentan los estadísticos descriptivos para las mismas variables, en donde sobresale el exceso de curtosis y baja desviación frente a la media.

Gráfico 6. Variables con correlación dinámica estacionaria desde el periodo 2011 al 2017. COP-IBR COP-VIX
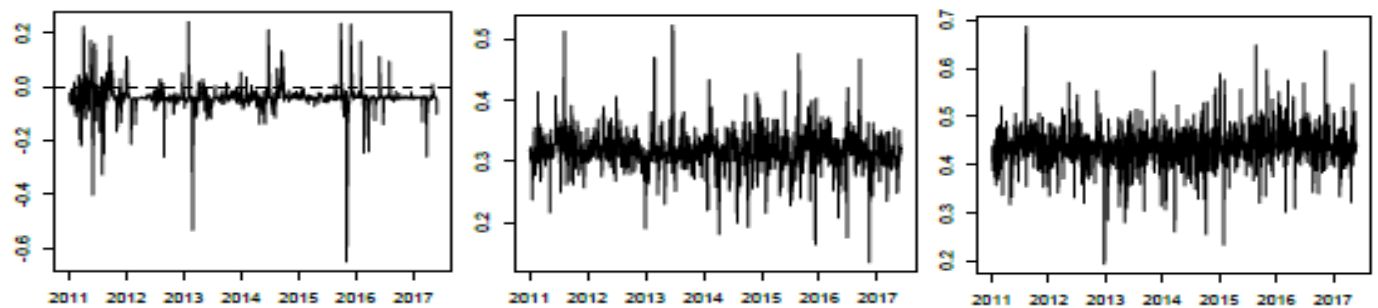

Fuente: Elaboración propia con datos de Bloomberg (2017). 
En el Gráfico 7, se presenta la evolución de las correlaciones para las demás variables con correlación dinámica, donde para el WTI, los TES con vencimiento 2024, los Tesoros con vencimiento 10 años, el USD/MXN, el índice MXEF, el USD/CLP, el Índice Colcap y el Índice DXY es evidente la dinámica de la dependencia temporal.

Gráfico 7. Correlaciones DCC históricas desde el período 2011 al 2017.

COP-WTI

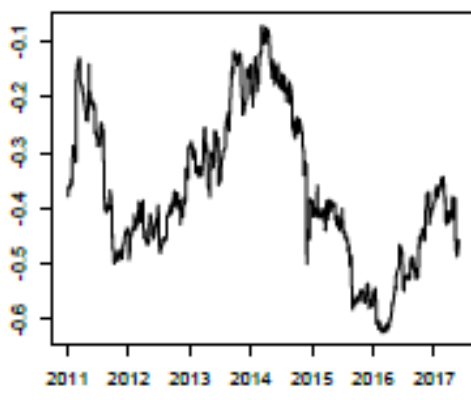

COP-MXN

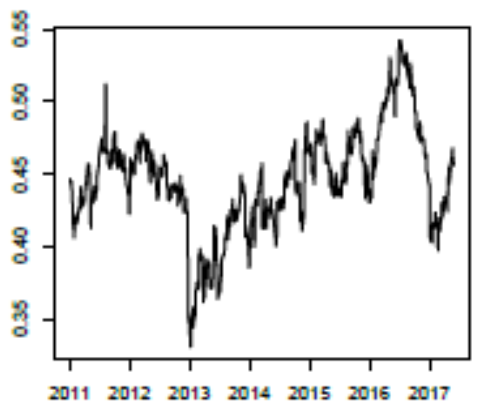

COP-TES24

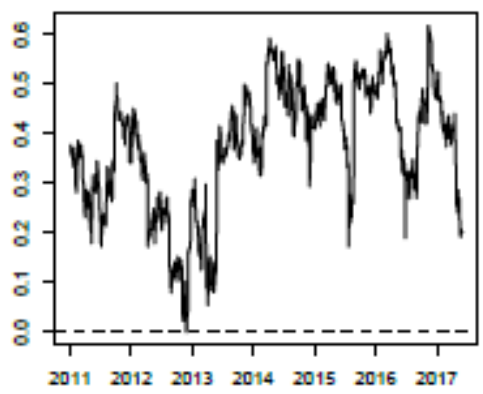

COPAMEF

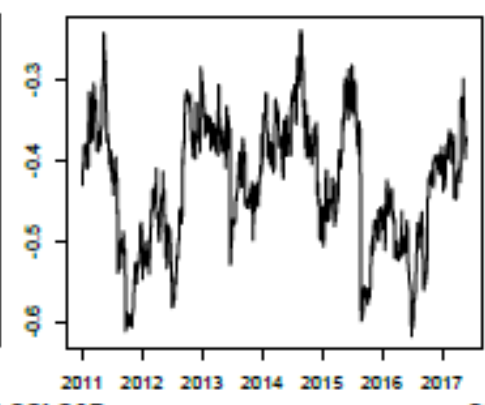

COP-TESOROS1OY

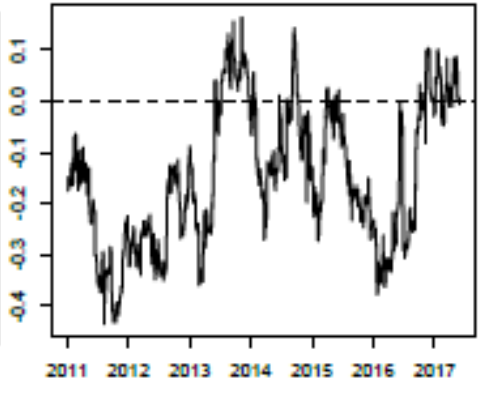

COP-CLP

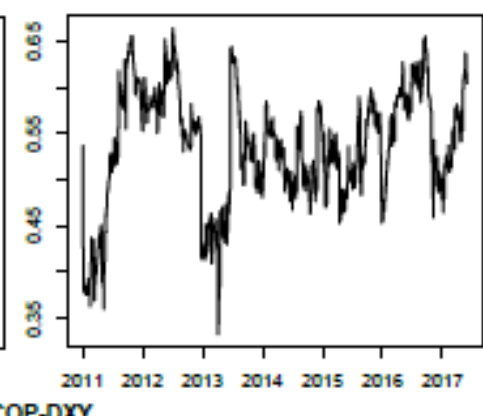

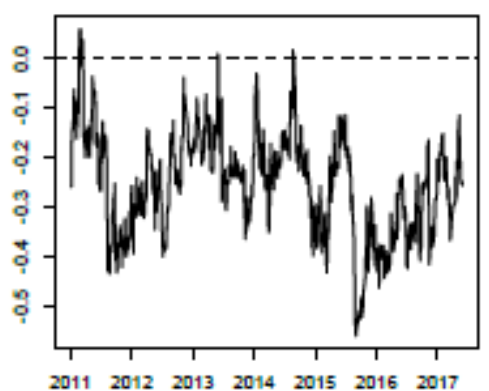

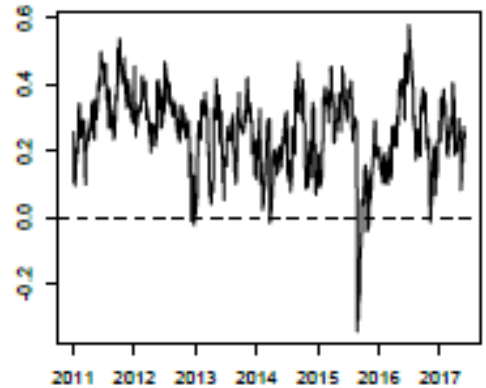

Fuente: Elaboración propia con datos de Bloomberg (2017).

El modelo DCC para las variables USD/COP - WTI permite inferir que a niveles de petróleo por encima de los 80 dólares por barril, la correlación se ubica entre un -30\% al -10\% y disminuye cuando se presenta un periodo importante de estabilidad en el precio del crudo tal como el periodo 2013 a 2014 en el que el crudo estuvo en niveles históricamente altos. De esta manera, en periodos de estabilidad para una de las variables más importante para los ingresos del país la fuente de correlación puede disminuir y adquieren importancia otras variables. Sin embargo, una vez se da el choque por la caída de los precios del petróleo a niveles mínimos en el 2015 la correlación llega a niveles cercanos al -60\%.

La correlación negativa no solo se da con los retornos del precio de petróleo, también para la tasa de los bonos del Tesoro a 10 años y los índices MXEF y Colcap con una media de $44 \%$ y $-25 \%$ respectivamente, cuando se dan valorizaciones (desvalorizaciones) en los índices se generan presiones de revaluación (devaluación), lo cual puede ser explicado por el apetito de inversionistas extranjeros en los activos locales generando flujos de compra (venta). Adicionalmente, en relación con los flujos al mercado accionario, se ha mencionado en 
apartados anteriores la existencia de una creencia en el mercado, donde se cree que el mercado accionario es el mejor indicador para anticipar el ciclo económico.

En el caso de la correlación con la tasa TES se presenta una fuerte dinámica que puede ser explicada por movimientos en la curva de rendimientos dado decisiones de política monetaria, Outlook de calificadoras como en el 2013 y por rebalanceo de índices internacionales de deuda emergente. A pesar de los cambios que ha tenido a lo largo del tiempo en promedio se ubica en 37\% positivo (Tabla 6), una de las correlaciones más altas para el USD/COP y con menor coeficiente de variación de la muestra. No obstante, para el año 2017 se encuentra en niveles mínimos, a razón de que el TES con vencimiento de 2024 había sido durante un largo periodo la referencia más líquida del mercado de deuda pública local por ser la referencia de 10 años según estándares internacionales, pero actualmente su vencimiento corresponde a 7 años dando lugar para que otras referencias capturen la liquidez que normalmente se destinaba a este título.

Tabla 6. Estadística descriptiva de las series de correlación dinámica DCC.

\begin{tabular}{lccccccccccc}
\hline & \multicolumn{10}{c}{ Correlación USD/COP versus - } \\
& WTI & TES24 & TESOROS & MXN & MXEF & CLP & Colcap & DXY & IBR & VIX & CDS10 \\
\hline \hline Media & -0.368 & 0.373 & -0.149 & 0.445 & -0.428 & 0.535 & -0.255 & 0.257 & -0.041 & 0.317 & 0.437 \\
Mediana & -0.395 & 0.399 & -0.158 & 0.447 & -0.418 & 0.540 & -0.246 & 0.271 & -0.041 & 0.317 & 0.437 \\
Máximo & -0.071 & 0.617 & 0.164 & 0.542 & -0.238 & 0.664 & 0.060 & 0.577 & 0.241 & 0.522 & 0.686 \\
Mínimo & -0.624 & 0.000 & -0.436 & 0.331 & -0.618 & 0.332 & -0.560 & -0.342 & -0.650 & 0.136 & 0.194 \\
Desviación & 0.135 & 0.128 & 0.138 & 0.036 & 0.079 & 0.063 & 0.106 & 0.119 & 0.054 & 0.029 & 0.035 \\
Asimetría & 0.255 & -0.553 & 0.135 & -0.121 & -0.251 & -0.449 & -0.097 & -0.836 & -2.376 & 0.243 & -0.059 \\
Curtosis & 2.223 & 2.619 & 1.993 & 3.618 & 2.395 & 2.808 & 2.965 & 5.270 & 31.608 & 10.387 & 11.090 \\
\hline \multicolumn{10}{c}{ Fuente: Elaboración propia con datos de Bloomberg (2017). }
\end{tabular}

El índice DXY es de gran relevancia para la formación de las tasas de cambio en el mundo por ser un indicador de la fortaleza del dólar frente a las principales divisas. La correlación observada para el periodo entre los retornos del DXY y los retornos USD/COP se ha ubicado generalmente entre un $20 \%$ y $40 \%$, con media $25 \%$, se considera que la relación entre ambas variables tiene memoria de largo plazo.

Por último, las variables con mayor media de correlación dinámica son USD/CLP (53\%) y USD/MXN (44\%), las cuales tienen una dependencia dinámica para el periodo de análisis con la tasa de cambio USD/COP que ha fluctuado desde 33\% hasta 66\%. Este resultado es congruente con los países de la región dada su dependencia a los precios de materias primas (Commodities) están expuestos a factores externos similares. Es importante resaltar que a pesar del nivel de correlación no es recomendable modelar a partir de las otras monedas de la región para evitar problemas de multicolinealidad con el índice DXY que recoge el movimiento del dólar a través de una canasta de monedas en el mundo.

\subsection{Aplicación del modelo ARIMAX-GARCH.}

Para la introducción de variables exógenas en el modelo ARIMA-GARCH con miras a mejorar la estimación, en primera instancia se realizó un análisis previo de correlaciones promedio (ver Tabla 1) y la aplicación de los modelos DCC con las principales variables que interactúan con la formación del par USD/COP. Posteriormente, se procedió a verificar el nivel de significancia de cada una de las variables que presentaban un nivel de correlación significativa y que en la práctica son observadas por los inversionistas para anticipar movimientos en la tasa de cambio. 
Una vez fueron identificadas las variables significativas como se estipula en el supuesto III de los modelos ARIMAX, se seleccionaron las siguientes variables: el índice DXY, los TES con vencimiento en julio 2024 y el WTI. Además, se verificó la condición de estacionariedad para los rendimientos diarios para garantizar el cumplimento del supuesto I de las estacionariedad de las series (Tabla 3).

En la identificación del modelo ARIMAX se evidencian clusters de volatilidad que, así como en el modelo ARIMA, se modelaron haciendo uno de los modelos ARCH. Sin embargo, también se incluyó la variable Dummy (D1), anteriormente descrita.

Antes de realizar un análisis del modelo ARIMAX, se presenta el Test de Causalidad Granger para identificar la causalidad entre las variables seleccionadas (exógenas) y USD/COP (endógena). Como se observa en la Tabla 7 cada uno de los retornos de las variables exógenas tienen un p-valor menor al 5\%, dando como resultado el rechazo de la hipótesis nula y se comprueba que causan a la los retornos diarios de los cierres USD/COP. Es muy importante verificar que la relación contraria no se cumple y esto permite afirmar que la selección de variables ha sido bien realizada y que no existen problemas de multicolinealidad como lo busca garantizar el supuesto IV de los modelos ARIMAX.

Tabla 7. Test de Causalidad de Granger.

\begin{tabular}{lccc}
\hline \multicolumn{1}{c}{ Hipótesis Nula } & Obs & F-Estadístico & Probabilidad \\
\hline \hline RDXY no causa a la Granger a RCOP & 1661 & 6.010 & 0.0025 \\
RCOP no causa a la Granger a RDXY & & 1.213 & 0.2975 \\
RTES24 no causa a la Granger a RCOP & 1661 & 8.407 & 0.0002 \\
RCOP no causa a la Granger a RTES24 & & 0.424 & 0.6548 \\
RWTI no causa a la Granger a RCOP & \multirow{2}{*}{1661} & 7.046 & 0.0012 \\
RCOP no causa a la Granger a RWTI & & 0.353 & 0.7024 \\
RTES24 no causa a la Granger a RDXY & 1661 & 0.834 & 0.4344 \\
RDXY no causa a la Granger a RTES24 & & 0.032 & 0.9683 \\
RWTI no causa a la Granger a RDXY & 1661 & 0.123 & 0.8847 \\
RDXY no causa a la Granger a RWTI & & 0.060 & 0.9419 \\
RWTI no causa a la Granger a RTES24 & \multirow{2}{*}{1661} & 2.265 & 0.1042 \\
RTES24 no causa a la Granger a RWTI & & 0.732 & 0.4811 \\
\hline
\end{tabular}

Fuente: Elaboración propia con datos de Bloomberg (2017).

Una vez se identificó la presencia de autocorrelación para la variable endógena, se estimó el modelo ARIMAX bajo la previa identificación del ARIMA $(9,1,0)$ y se incluyeron las variables exógenas. Al evaluar el correlograma de los residuos al cuadrado de esta estimación en media (Anexo 6), se evidenció la presencia de dependencia temporal para la varianza, lo cual se corroboró por medio del Test de Heterocedasticidad - ARCH y se afirmó la presencia de efectos ARCH. Esto hace necesario realizar la modelación por medio de la familia ARCH para corregir la dependencia temporal de la varianza en el tiempo.

La estimación del modelo bajo los parámetros ARCH, generan como modelo propuesto un ARIMAX $(9,1,0)$ - GARCH $(1,1)$, donde a diferencia del modelo ARIMA $(9,1,0)$ - GARCH $(1,1)$, no es significativo el rezago AR (1).

Por último, para garantizar la no autocorrelación serial de los residuos y los residuos al cuadrado, se evaluaron los correlogramas de los mismos (Anexo 7). En este caso, se obtuvieron p-valores mayores al nivel de confianza con el cual se acepta la hipótesis nula, que indica que no hay autocorrelación serial ni en media ni en varianza, razón por la que las estimaciones realizadas son adecuadas para la realización de pronósticos. 
En la Tabla 8, se presentan los resultados del modelo USD/COP que arrojó un DurbinWatson de 1.943312, el cual se encuentra en el rango contemplado según las tablas de significancias para un modelo con 1650 observaciones y cinco variables exógenas, que requiere un Durbin-Watson inferior a 1.9155 y superior a 1.9249. De esta manera, se da cumplimiento al supuesto II para la estimación de modelos ARIMAX, dado que el Durbin-Watson del modelo estimado no presenta evidencia estadística de autocorrelación.

Tabla 8. Resultados del Modelo ARIMAX - GARCH.

\begin{tabular}{ccccc}
\hline \multicolumn{5}{c}{ Ecuación de la Media } \\
\hline Variable & Coeficiente & Error Estándar & Estadístico -Z & Probabilidad \\
\hline C & 0.000113 & 0.000132 & 0.856268 & 0.3918 \\
RDXY(-2) & 0.070795 & 0.026411 & 2.680478 & 0.0074 \\
RTES24(-1) & 0.064075 & 0.010809 & 5.928041 & 0.0000 \\
RWTI(-1) & -0.019595 & 0.007479 & -2.619993 & 0.0088 \\
D1 & 0.006156 & 0.001473 & 4.179949 & 0.0000 \\
AR(9) & 0.059423 & 0.025215 & 2.356681 & 0.0184 \\
\hline \multicolumn{5}{c}{ Ecuación de la Varianza } \\
\hline Variable & Coeficiente & Error Estándar & Estadístico-Z & Probabilidad \\
\hline C & $1.15 E-07$ & 0.000000 & 0.0165 \\
RESID(-1)^2 & 0.056433 & 0.006132 & 9.39709 & 0.0000 \\
GARCH(-1) & 0.943792 & 0.005564 & 0.0000 \\
\hline R-squared & 0.019825 & Mean dependent var & 0.000256 \\
Adjusted R-squared & 0.016860 & S.D. dependent var & 0.007449 \\
S.E. of regression & 0.007386 & Akaike info criterion & -7.380615 \\
Sum squared resid & 0.090185 & Schwarz criterion & -7.351244 \\
Log likelihood & 6131.220 & Hannan-Quinn criter. & -7.369729 \\
Durbin-Watson stat & 1.943312 & & \\
\hline
\end{tabular}

Fuente: Elaboración propia con datos de Bloomberg (2017).

Una vez se garantiza el cumplimiento de los supuestos de modelo ARIMAX se presentan las siguientes ecuaciones que permiten generar los pronósticos para las series.

\section{Ecuación Media Modelo ARIMAX}

$$
\begin{aligned}
& \Delta U S D / C O P_{t}=\Delta y_{t} \\
& \Delta y_{t}=0.00011+0.070795 R D X Y_{t-2}+0.064075 R T E S 24_{t-1}-0.019595 R W T I_{t-1}+ \\
& 0.059423 y_{t-9}+0.006156 \mathrm{D} 1
\end{aligned}
$$

\section{Ecuación Varianza modelo GARCH}

$$
\sigma_{t}^{2}=1.15 \mathrm{E}-07+0.056433 \varepsilon_{t-1}^{2}+0.943792 \sigma_{t-1}^{2}
$$

Según el modelo obtenido, el índice DXY es una de las variables exógenas que más relevancia tiene para explicar el comportamiento del par USD/COP y esto es coherente con la situación actual de la globalización de los mercados financieros y más para el caso de Colombia donde los principales tenedores de la deuda soberana (TES) después de los fondos de pensiones y cesantías son los fondos de capital extranjero que desde el 2011 han pasado de tener una partición cercana al 5\% para alcanzar niveles superiores el 25\% del total de deuda soberana en pesos, según reportes de tenedores de deuda publicados mensualmente por el Banco de la República. Por esta razón, el DXY es un índice que captura el valor del dólar en el mundo y que se ve afectado por los temas geopolíticos, políticos, normalización monetaria de la FED, crecimiento mundial y precio de las materias primas, lo que genera un efecto inmediato en la devaluación o revaluación de monedas de economías emergentes como Colombia dependiente altamente de flujos de capital extranjero. Así, un movimiento del $1 \%$ en los rendimientos del 
DXY genera un efecto directamente proporcional del 7\% en los rendimientos de la tasa de cambio.

Al analizar otras variables exógenas de relevancia para la determinación del tipo de cambio, tal como el petróleo por medio de la referencia WTI, se observa la correlación negativa que tiene con la paridad USD/COP, donde a mayores precios de petróleo menor será el avance en términos de retornos diarios para la tasa de cambio, siendo consecuentes con la relevancia que tiene el petróleo dentro del PIB de Colombia cercano al 40\%. Así mismo, la variable dummy (D1) también permite incorporar los hechos estilizados por las reuniones de la OPEP que generaron fuertes tensiones en el 2015 que se reflejó en un avance en los precios del petróleo y tuvo como efecto la revaluación de la moneda colombiana.

Por otro lado, el comportamiento de los TES permite capturar el apetito por riesgo versus la rentabilidad ofrecida que tienen los inversionistas extranjeros en el país y la confianza que les genera en el medio plazo la economía local para realizar inversiones de portafolio.

Así mismo, los retornos diarios de nivel de tipo de cambio para el regazo significativo de nueve días siguen siendo de gran importancia para capturar la tendencia de la tasa de cambio en el mercado y ajustar el modelo a los movimientos estacionarios propios de la serie.

En el siguiente apartado se presentan los pronósticos muestrales y extra muestrales para poder discernir sobre qué modelo presenta mejor ajuste para el tipo de cambio colombiano.

\subsection{Pronósticos de los modelos estimados.}

Se realizaron pronósticos muestrales para 96 días que corresponden al periodo del 2 de enero del 2017 al 15 de mayo del 2017 y extramuestrales para 24 días que corresponden al periodo del 15 de mayo del 2017 al 15 de junio del 2017 con el objetivo de identificar cuál es el modelo que mejor se ajusta al nivel de USD/COP observado.

A partir de la observación del Gráfico 8 de pronósticos para los modelos ARIMAGARCH y ARIMAX-GARCH del USD/COP observado para el periodo, se evidencia que los pronósticos muestrales para ambos modelos presentan un ajuste muy cercano a la formación observada de la tasa de cambio y adicionalmente los movimientos de ambos modelos son muy ajustados entre sí. En el periodo de pronóstico extra muestral a partir del 15 de mayo de 2017 se presentan diferencias importantes contra el cierre observado por ambos modelos, con una mayor desviación para el pronóstico desde el modelo ARIMA-GARCH. Esto hace evidente la deficiencia del modelo donde presume un nivel de estabilidad en la variable en el corto plazo y no se capturan los cambios de volatilidad. En contraste, como se presenta en la Tabla 9 el modelo ARIMAX permite ajustarse mucho más a los movimientos de tendencia por cada periodo que efectivamente se observaron en los precios de cierre USD/COP. 
Gráfico 8. Pronósticos Modelos ARIMA y ARIMAX.

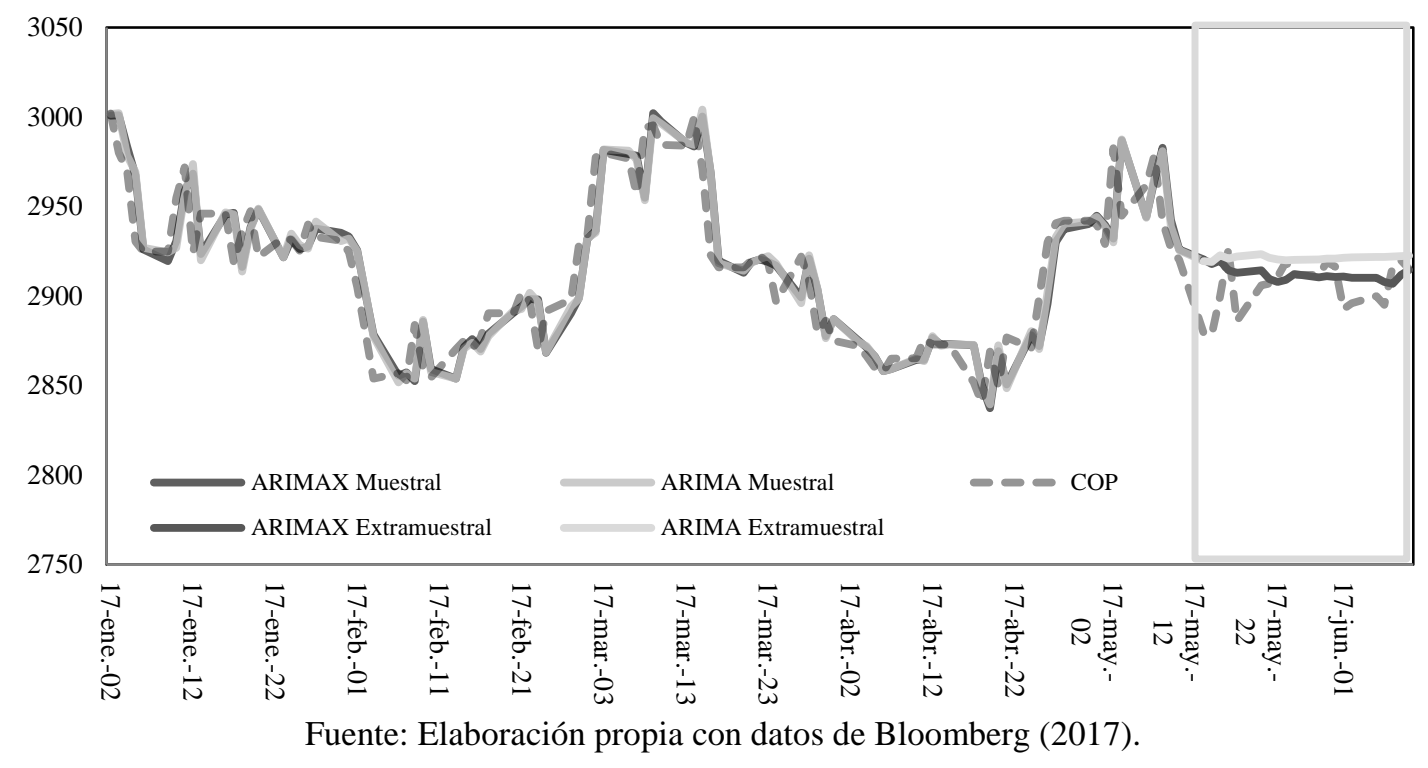

Tabla 9. Valores de los pronósticos extramuestrales ARIMA-GARCH y ARIMAX-GARCH.

\begin{tabular}{cccr}
\hline Fecha & $\begin{array}{c}\text { USD/COP } \\
\text { Observado }\end{array}$ & $\begin{array}{c}\text { ARIMA } \\
(9,1,0)\end{array}$ & $\begin{array}{c}\text { ARIMAX } \\
(9,1,0)\end{array}$ \\
\hline \hline $15 / 05 / 2017$ & 2879.00 & 2919.62 & 2920.36 \\
$16 / 05 / 2017$ & 2878.60 & 2919.05 & 2917.87 \\
$17 / 05 / 2017$ & 2899.89 & 2922.77 & 2919.70 \\
$18 / 05 / 2017$ & 2926.00 & 2920.84 & 2914.45 \\
$19 / 05 / 2017$ & 2885.90 & 2922.01 & 2913.08 \\
$22 / 05 / 2017$ & 2905.95 & 2923.42 & 2914.35 \\
$23 / 05 / 2017$ & 2907.00 & 2921.35 & 2909.41 \\
$24 / 05 / 2017$ & 2911.00 & 2920.35 & 2907.93 \\
$25 / 05 / 2017$ & 2919.00 & 2920.03 & 2909.16 \\
$26 / 05 / 2017$ & 2911.75 & 2920.18 & 2912.32 \\
$29 / 05 / 2017$ & 2911.75 & 2920.38 & 2910.34 \\
$30 / 05 / 2017$ & 2919.00 & 2920.86 & 2911.26 \\
$31 / 05 / 2017$ & 2916.40 & 2920.99 & 2910.70 \\
$01 / 06 / 2017$ & 2892.85 & 2921.29 & 2911.02 \\
$02 / 06 / 2017$ & 2896.00 & 2921.63 & 2910.28 \\
$05 / 06 / 2017$ & 2900.00 & 2921.74 & 2910.26 \\
$06 / 06 / 2017$ & 2895.00 & 2921.90 & 2907.92 \\
$07 / 06 / 2017$ & 2916.50 & 2922.11 & 2906.85 \\
$08 / 06 / 2017$ & 2920.00 & 2922.35 & 2911.74 \\
$09 / 06 / 2017$ & 2915.00 & 2922.60 & 2914.73 \\
$12 / 06 / 2017$ & 2933.00 & 2922.87 & 2916.06 \\
$13 / 06 / 2017$ & 2933.35 & 2923.12 & 2916.85 \\
$14 / 06 / 2017$ & 2935.50 & 2923.38 & 2914.81 \\
$15 / 06 / 2017$ & 2953.25 & 2923.65 & 2919.19 \\
\hline Fuente: El & 200 \\
\hline
\end{tabular}

Fuente: Elaboración propia con datos de Bloomberg (2017).

Con el fin de identificar estadísticamente el modelo con un menor error medio para los dos grupos de pronósticos, se contrastaron los errores medios y el coeficiente de desigualdad Theil que mide los errores medios en términos relativos y observados al generar los pronósticos (Tabla 10). 
Tabla 10. Errores de pronóstico de los modelos estimados.

\begin{tabular}{lcccrrr}
\hline & $\begin{array}{c}\text { ARIMA- } \\
\text { GARCH }\end{array}$ & $\begin{array}{c}\text { ARIMAX- } \\
\text { GARCH }\end{array}$ & & $\begin{array}{c}\text { ARIMA- } \\
\text { GARCH }\end{array}$ & $\begin{array}{c}\text { ARIMAX- } \\
\text { GARCH }\end{array}$ \\
\hline Media Error Absoluto & \multicolumn{2}{c}{ Muestrales } & & Extramuestrales \\
\hline Media Error Absoluto \% & 0.50634 & 14.4911 & & 16.3032 & 14.1785 \\
Coeficiente Theil & 0.0033 & 0.0032 & & 0.0034 & 0.0031 \\
\hline
\end{tabular}

Fuente: Elaboración propia con datos de Bloomberg (2017).

Según las medidas desviación del modelo frente a los valores observados en ambos grupos de pronósticos muestrales y extramuestrales, es posible afirmar que el modelo ARIMAX-GARCH presenta un mejor ajuste a la variable USD/COP y se realizó una adecuada selección de variables independientes que permitieron ajustar el modelo ARIMAX- GARCH en un mayor porcentaje que si solo se realizaran los pronósticos desde el modelo ARIMAGARCH, es decir, que los retornos de la variable USD/COP por sí solos no son el mejor estimador para su comportamiento futuro. Adicionalmente a partir de los criterios de selección de modelos, se corrobora que el mejor modelo es un ARIMAX $(9,1,0)$-GARCH $(1,1)$, al obtener mejores resultados en todos los casos (Tabla 11).

Tabla 11. Criterios de selección.

\begin{tabular}{|c|c|c|}
\hline Modelo / Criterios & $\begin{array}{l}\text { ARIMA }(9,1,0) \\
\text { GARCH }(1,1)\end{array}$ & $\begin{array}{c}\text { ARIMAX }(9,1,0) \\
\text { GARCH }(1,1)\end{array}$ \\
\hline R-squared & 0.009248 & 0.019825 \\
\hline Adjusted R-squared & 0.007453 & 0.016860 \\
\hline Akaike info criterion & -7.369054 & -7.380615 \\
\hline Schwarz criterion & -7.346222 & -7.351244 \\
\hline Hannan-Quinn criter. & -7.360592 & -7.369729 \\
\hline
\end{tabular}

\section{Conclusiones.}

La creciente importancia que juega el riesgo y la incertidumbre en la teoría económica y financiera ha conllevado que sea de interés de inversionistas, gobierno y el público en general, el desarrollo de nuevas técnicas que permitan el pronóstico de la tasa de cambio. Principalmente en países donde el tipo de cambio tiene algún nivel de flexibilidad como para el caso de estudio la tasa de cambio en Colombia. Es por ello que no solo los modelos de tasa de cambio de equilibrio, el análisis técnico o los modelos de microestructura de mercado suplen la necesidad de pronósticos eficientes que se ajusten a las condiciones propias de la variable de estudio. Las aproximaciones econométricas de series de tiempo que permitan capturar las dependencias temporales, correlaciones dinámicas y volatilidades heterocedásticas de las series financieras han obtenido gran relevancia para el pronóstico de activos financieros como el tipo de cambio.

En la actualidad, existen diversas fuentes de volatilidad para los mercados financieros en general, tales como los discursos de los miembros de la FED, las decisiones del Banco Central Europeo (BCE) y en general las políticas monetarias en el mundo que generan incertidumbre a consecuencia de los futuros movimientos de la hoja de balance, que modifica la liquidez global que ha estado en su nivel más boyante desde el 2009, junto con riesgos geopolíticos como las tensiones entre Estados Unidos y Corea del Norte, cambios de gobierno a nivel mundial con un enfoque más populista en general. Todos estos eventos dan relevancia al desarrollo de modelos que incorporen cada vez más hechos estilizados que introducen choques en volatilidad. 
La tasa de cambio de un país está influenciada por diferentes variables financieras, políticas y variables macroeconómicas que hacen de su pronóstico un reto en la selección más eficiente de éstas. Por esta razón, se realizó un amplio estudio de variables con un nivel alto de correlación con el par USD/COP (Anexo 1). Sin embargo, la medida de correlación lineal convencional de Pearson ofrece señales para un momento estático en el tiempo, lo que no recoge la relación lineal de dependencia dinámica entre un par de variables, sino que se limita a mostrar una relación lineal promedio. Es así como fue de interés de esta investigación el análisis de los co-movimientos de las variables por medio de la aplicación de los modelos DCC para un análisis dinámico de la correlación entre los retornos diarios del tipo de cambio y las series Índice DXY, Índice Colcap, CDS 10 años Colombia, Índice IBR, Tesoros con vencimiento 10 años, índice MXEF, WTI, TES con vencimiento 2024, índice VIX, USD/CLP y USD/MXN.

Los resultados obtenidos permiten concluir que el tipo de cambio en Colombia tiene una correlación dinámica persistente en el tiempo con las principales variables de estudio, por ejemplo, para el caso de la dependencia temporal entre USD/COP y el WTI en periodos amplios de desvalorizaciones a consecuencia de choques de volatilidad se presentaron incrementos significativos en la correlación, ubicándose en niveles superiores al $-60 \%$, mientras que en periodos de baja volatilidad otras variables adquieren mayor relevancia, como los índices bursátiles y el comportamiento de las monedas de la región. Es importante concluir que la aplicación del modelo DCC para las variables IBR, VIX y CDS 10 años en relación con el par USD/COP permitió inferir que su correlación es constante en el tiempo y, por lo tanto, dicha relación no se ve fuertemente afectada por cambios en el entorno financiero.

Colombia siendo uno de los países de la región con más vulnerabilidad macroeconómica por su déficit fiscal, bajo crecimiento económico, riesgo político y la sensibilidad de los actuales inversionistas a realizar una salida masiva de flujos de inversión, se convierte en un escenario propicio para la aplicación los modelos econométricos que incorporen cierto grado de incertidumbre. Es así como se realizó la estimación de un modelo de tipo de cambio por medio de la aplicación de los modelos autorregresivos ARIMA-GARCH y ARIMAX-GARCH. Este último, dado que fue interés de esta investigación incorporar variables macroeconómicas, financieras, políticas, entre otras que de alguna u otra forma interactuaran con la formación de la tasa de cambio en Colombia. Los resultados encontrados sugieren una evidencia a favor de los modelos ARIMAX-GARCH, pues en el modelo calibrado solo desde la variable dependiente USD/COP por sí misma no es el mejor estimador para las proyecciones fuera de muestra al no incorporar hechos estilizados.

Como resultado, en el proceso de modelación fueron seleccionadas las variables DXY, TES con vencimiento en 2024 y el precio del petróleo por medio de la referencia WTI, variables que actualmente presentan un nivel de correlación alta con la formación de cierre para USD/COP y que son comúnmente seguidas por los inversionistas para anticipar movimientos en la tasa de cambio. Sin embargo, los activos financieros que tienen influencia de un grupo tan amplio de variables cambian contantemente los niveles de correlación entre sí.

El modelo ARIMAX $(9,1,0)-G A R C H(1,1)$ presentó un mejor nivel de ajuste no solo para el periodo de pronósticos muestrales sino para los pronósticos extramuestrales, con un margen de error medio mucho menor que para la serie de pronósticos ARIMA-GARCH, el modelo permite pronosticar el comportamiento dinámico de la serie en el tiempo y aunque existen diferencias frente a los cierres observados para el par USD/COP, los pronósticos son congruentes con la tendencia de corto plazo de la serie observada; la identificación adecuada de las variables con influencia en la tasa de cambio hacen que este modelo sea una fuente eficiente de información para la toma de decisiones.

En futuras investigaciones se recomienda incorporar al modelo de predicción de tipo de cambio colombiano el efecto de la economía subterránea existente como consecuencia de las actividades ilícitas que generan movimientos de flujos en moneda extranjera. Este fenómeno 
afecta el cálculo del producto interno bruto del país, la balanza cambiaria y, como estos recursos permean en la economía real, pueden generar presiones en la formación de la tasa de cambio, que no pueden ser explicadas por otras variables nominales.

\section{Referencias}

Abhyankar, A., Sarno, L., \& Valente, G. (2005). Exchange rates and fundamentals: Evidence on the economic value of predictability. Journal of International Economics, 66(2), 325-348.

Andrews, B.H., \& Dean, M.D. (2013). Building ARIMA and ARIMAX Models for Predicting Long-Term Disability Benefit Application Rates in the Public / Private Sectors Sponsored by Society of Actuaries Health Section Prepared by University of Southern Maine. Building ARIMA and ARIMAX Models for Predicting Long-Term Disability Benefit Application Rates in the Public/Private Sectors Sponsored.

Anggraeni, W., Vinarti, R.A., \& Kurniawati, Y.D. (2015). Performance Comparisons between Arima and Arimax Method in Moslem Kids Clothes Demand Forecasting: Case Study. Procedia Computer Science, 72, 630-637.

Babu, A.S., \& Reddy, B.A. (2015). Exchange Rate Forecasting using ARIMA, Neural Network and Fuzzy Neuron. Journal of Stock \& Forex Trading, 4(3), 1-5.

Bloomberg, L.P. (2017). Stock last price from 1/1/11 to 06/30/17. Bloomberg Terminal. Recuperado de: https://www.bloomberg.com/

Bollerslev, T. (1986). Generalized autoregressive conditional heteroskedasticity. Journal of Econometrics, 31(3), 307-327.

Box, G. E., \& Jenkins, G.M. (1970). Time series analysis, control, and forescasting. San Francisco, CA: Holden Day, 3226(3228), 10.

Cardenas, M. (1997). La tasa de cambio en Colombia. Cuadernos de Fedesarrollo, No. 012740. Bogotá

Carr, P., \& Wu, L. (2007). Theory and evidence on the dynamic interactions between sovereign credit default swaps and currency options. Journal of Banking and Finance, 31(8), 23832403.

Cassel, G. (1922). Money and foreign exchange after 1914. London: Constable and Company Limited, pp. 101 - 170.

Chavarro, F. (2008). Política monetaria en Colombia, 1999-2000. Revista Criterio Libre, 9, $73-$ 93.

Chavarro, F., \& Grautoff, M. (2010). El trilema de la Banca Central Colombiana: un problema intertemporal. Criterio Libre, 8, 15-30. Recuperado de: http://scholar.google.com/scholar?hl=en\&btnG=Search\&q=intitle:No+Title\#0

Chiang, T.C., Jeon, B.N., \& Li, H. (2007). Dynamic correlation analysis of financial contagion: Evidence from Asian markets. Journal of International Money and Finance, 26(7), 12061228. 
Chinn, M.D., \& Meese, R.A. (1995). Banking on currency forecasts: How predictable is change in money? Journal of International Economics, 38(1-2), 161-178.

Chong, M., \& Aguilar, R. (2016). Proyección de Series de Tiempo para el Consumo de la Energía Eléctrica a Clientes Residenciales en Ecuador, 29(Julio), 56-76.

Davis, J.S. (2017). External debt and monetary policy autonomy. Ensayos Sobre Política Económica, 35, 53-63.

Echavarría, J.J., Misas, M., \& López, E. (2007). La Tasa de Cambio Real de Equilibrio en Colombia y su Desalineamiento: Estimación a través de un modelo SVEC. Borradores de Economía, 472, 2-37.

Echavarría, J.J., Vásquez, D., \& Villamizar, M. (2005). The Real Exchange Rate in Colombia: Too Far from Equilibrium? Ensayos Sobre Política Económica, 49, 134-191.

Ecopetrol S.A. (2016, 14 de junio). Recuperado de: http://www.ecopetrol.com.co/wps/portal/es/ecopetrol-web/nuestra-empresa/quienessomos/acerca-de-ecopetrol/nuestra-historia

Edwards, S., \& Savastano, M.A. (1999). Exchange Rates in Emerging Economies: What do we Know? What do we need to know? National Bureau of Economic Research Working Paper Series.

Ehrmann, M., \& Fratzscher, M. (2005). Exchange rates and fundamentals: New evidence from real-time data. Journal of International Money and Finance, 24(2), 317-341.

Engel, C., \& West, K.D. (2005). Exchange Rates and Fundamentals. Journal of Political Economy, 113(3), 485-517.

Engle, R. (1982). Autoregressive Conditional Heteroscedasticity With Estimates of the Variance of United Kingdom Inflation1. Econometrica, 50(4), 987-1007.

Engle, R. (2002). Dynamic Conditional Correlation. Journal of Business \& Economic Statistics, 20(3), 339-350.

Evans, M.D.D. (2010). Order flows and the exchange rate disconnect puzzle. Journal of International Economics, 80(1), 58-71.

Fahimifard, S.M., Homayounifar, M., Sabouhi, M., \& Moghaddamnia, A.R. (2009). Comparison of ANFIS, ANN, GARCH and ARIMA Techniques to Exchange Rate Forecasting. Journal of Applied Sciences, 9(20), 3641-3651.

Fama, E.F. (1965). The Behavior of Stock-Market Prices. The Journal of Business, 38(1), 34105.

Fernández-Rodríguez, F., Sosvilla-Rivero, S., \& Andrada-Félix, J. (1999). Exchange-rate forecasts with simultaneous nearest-neighbour methods: evidence from the EMS. International Journal of Forecasting, 15, 383-392.

Fernández-, F., González, C., \& Sosvilla, S. (2000). On the profitability of technical trading rules based on artificial neural networks: Economics Letters, 69(1), 89-94. 
Frenkel, J.A., \& Mussa, M.L. (1985). Chapter 14 Asset markets, exchange rates and the balance of payments, Handbook of International Economics, 2, 679-747.

Gioqinang, Z., \& Hu, M.Y. (1998). Neural network forecasting of the British Pound/US Dollar exchange rate. Omega, 26(4), 495-506.

Gómez, J., \& Hernández, J.M. (2011). Composición cambiaria y Poder Adquisitivo de las reservas internacionales. Borradores de Economía, Banco de La Republica, (654).

González, C. (2003). Nuevas perspectivas del análisis técnico de los mercados bursátiles mediante el aprendizaje automático. Aplicaciones al índice general de la bolsa de Madrid. Resarch Gate. Recuperado de: http://hdl.handle.net/10553/2156

Granger, C.W. (1986). Investigating Causal Relations by Econometric Models and Crossspectral Methods. Econometrica: Journal of the Econometric Society, 37(3), 424-438.

Hassan, M. K., Kayhan, S., \& Bayat, T. (2017). Does credit default swap spread affect the value of the Turkish LIRA against the U.S. dollar? Borsa Istanbul Review, 17(1), 1-9.

Jalil, M.A., \& Misas, M. (2007). Evaluaciòn de pronòsticos del tipo de cambio utilizando redes neuronales y funciones de pèrdida asimètricas. Revista Colombiana de Estadistica, 30(1), 143-161.

Julio, B., \& Yook, Y. (2016). Policy Uncertainty , Irreversibility , and Cross-Border Flows of Capital Federal Reserve Board of Governors. Journal of International Economics, 103, 13-26.

Kamruzzaman, J., \& Sarker, R.A. (2003). Forecasting of currency exchange rates using ANN: a case study. Neural Networks and Signal Processing, 1, 793-797.

Kim, B.-H., Kim, H.-K., \& Oh, K.-Y. (2009). The purchasing power parity of Southeast Asian currencies: A time-varying coefficient approach. Economic Modelling, 26(1), 96-106.

Krugman, P.R., Obstfeld, M., \& Melitz, M.J. (2012). Economía international: Teoría y política. Pearson.

Lothian, J.R., \& Taylor, M.P. (1996). Real exchange rate behavior: the recent float from the perspective of the past two centuries. Journal of Political Economy, 104(3), 488-509.

MacDonald, R., \& Marsh, I.W. (1997). On Fundamentals and Exchange Rates: A Casselian Perspective. The Review of Economics and Statistics, 79(4), 655-664.

Majhi, R., Panda, G., \& Sahoo, G. (2009). Efficient prediction of exchange rates with low complexity artificial neural network models. Expert Systems with Applications, 36(1), 181189.

Malkiel, B.G. (2015). A Random Walk Down Wall Street: The Time-Tested Strategy for Successful Investing (10th Edition). W W Norton \& Co Inc, 496.

Mandelbrot, B. (1963). The Variation of Certain Speculative Prices The Variation of Certain Speculative Prices. The Journal of Business, 36(4), 394-419.

Marsh, I.W., \& Sarno, L. (2012). Handbook of Exchange Rates. Handbook of Exchange Rates. 
Medeiros, R., \& Júnior, J.L.R. (2009). O Relacionamento entre a Taxa de Câmbio R \$/US \$ e Fundamentos (No. wpe_190). Insper Working Paper, Insper Instituto de Ensino e Pesquisa. IBMEX Sao Paulo.

Meese, R., \& Rogoff, K. (1983). The Out-of-Sample Failure of Empirical Exchange Rate Models: Sampling Error or Misspecification? In Exchange rates and international macroeconomics. University of Chicago Press, pp. 67-112.

Murcia, A., \& Rojas, D. (2015). Determinantes de la tasa de cambio en Colombia: un enfoque de microestructura de mercados. Ensayos Sobre Política Económica, 33(74), 207-219.

One Financial Markets, \& CB Financial Services Ltd. (2012). UK Brent Oil. Recuperado de: https://www.onefinancialmarkets.com/market-library/uk-brent-oil

Ordoñez, M.L. (2016). Riesgo y volatilidad del tipo de cambio en Colombia, evaluación y pronóstico 2000 - 2006. Revista FACE, 2, 33-57.

Pacelli, V. (2012). Forecasting Exchange Rates: a Comparative Analysis. International Journal of Business and Social Science, 3(10), 145-156.

Panda, C., \& Narasimhan, V. (2007). Forecasting exchange rate better with artificial neural network. Journal of Policy Modeling, 29(2), 227-236.

Parisi, A., Parisi, F., \& Cañas, E. (2002). Reglas simples de analisis tecnico y modelos autprregresivos en el mercado cambiario chileno entre 1995 al 2001. Estudios de Administración, 9(2), 69-88.

Pektaş, A.O., \& Kerem, H. (2013). ANN hybrid model versus ARIMA and ARIMAX models of runoff coefficient. Journal of Hydrology, 500, 21-36.

Peter, D.., \& Silvia, P. (2012). ARIMA vs. ARIMAX - which approach is better to analyze and forecast macroeconomic time series? Proceedings of 30th International Conference Mathematical Methods in Economics, 2, 136-140.

Reboredo, J.C. (2012). Modelling oil price and exchange rate co-movements. Journal of Policy Modeling, 34(3), 419-440.

Rime, D., Sarno, L., \& Sojli, E. (2010). Exchange rate forecasting, order flow and macroeconomic information. Journal of International Economics, 80(1), 72-88.

Rojas, M.E., \& Duque, A.F. (2014). Colombia sobre el producto interno bruto , la inversión extranjera directa y la balanza comercial. Escuela de Ingenieria de Antioquia. Recuperado de: http://repository.eia.edu.co/bitstream/11190/238/1/ADMO0817.pdf

Samuelson, P.A. (1965). Proof that properly anticipated prices fluctuate randomly. IMR; Industrial Management Review, 6(2), 41-49.

Serwa, D., \& Bohl, M.T. (2005). Financial contagion vulnerability and resistance: A comparison of European stock markets. Economic Systems, 29(3), 344-362.

Stein, J. L., \& Allen, P. R. (1997). Fundamental determinants of exchange rates. United Kingdom: Clarendon Press, Oxford. 
Syllignakis, M.N., \& Kouretas, G.P. (2011). Dynamic correlation analysis of financial contagion: Evidence from the Central and Eastern European markets. International Review of Economics \& Finance, 20(4), 717-732.

Taylor, M.P. (2009). Editorial: Long-run purchasing power parity and real exchange rates: introduction and overview. Applied Economics Letters, 16(1), 1-4.

Tosoni, G.A. (2011). Necessary Levels, Costs and Policies for International Reserves in Latin America. Economía Mexicana Nueva Época, XX(1), 145-180. Recuperado de: http://ideas.repec.org/a/emc/ecomex/v20y2011i1p145-180.html

Uribe, J., Jiménez, D., \& Fernández, J. (2015). Regímenes de volatilidad del tipo de cambio en Colombia e intervenciones de política, $\operatorname{LXXIV(100),~1-31.~}$

Velásquez, D.J., \& González, L.M. (2006). Modelado del índice de tipo de cambio real colombiano usando redes neuronales artificiales. Cuadernos de Administración, 19(32), 319-336. Recuperado de: http://www.redalyc.org/articulo.oa?id=20503213

Wu, C.C., Chung, H., \& Chang, Y.H. (2012). The economic value of co-movement between oil price and exchange rate using copula-based GARCH models. Energy Economics, 34(1), 270-282.

Zalduendo, J. (2006). Determinants of Venezuela's Equilibrium Real Exchange Rate. IMF Working Paper, WP/06/74, 3-17. 
Anexos

\section{Anexo 1. Descripción de las variables exógenas analizadas desde su impacto a la tasa de cambio en Colombia.}

\begin{tabular}{|c|c|}
\hline Variable & Descripción \\
\hline CDS & $\begin{array}{l}\text { Credit Defaul Swap es un derivado financiero el cual representa el } \\
\text { intercambio de riesgo crédito de una nación con otra, en términos de país } \\
\text { se intercambia el riesgo país de Colombia contra el de Estados Unidos. } \\
\text { Ésta es una variable de seguimiento constante por inversionistas, es la } \\
\text { prima de riesgo y brinda señales del mercado de la confianza de los } \\
\text { inversionistas por un emisor. En otras palabras el CDS es conocido como } \\
\text { la prima de riesgo (Ver Gráfico 1) } \\
\text { En el caso de correlación con la tasa de cambio, observamos que los } \\
\text { CDS al representar el riesgo país ajustado día a día a las condiciones de } \\
\text { mercado, influencia el comportamiento de la tasa de cambio por medio } \\
\text { de los flujos de capital. }\end{array}$ \\
\hline Órdenes del mercado & $\begin{array}{l}\text { El mercado cambiario en Colombia está conformado por todas las } \\
\text { operaciones de negociación de la divisa peso/dólar realizadas a través de } \\
\text { los Intermediarios del Mercado Cambiario (IMC), los cuales son } \\
\text { conformados por Bancos Comerciales, los bancos hipotecarios, las } \\
\text { corporaciones financieras, las compañías de financiamiento comercial, la } \\
\text { FEN, Bancoldex, las cooperativas Financieras, las sociedades } \\
\text { comisionistas de Bolsa y las casas de cambio. } \\
\text { Los análisis de microestructura lo que buscan es medir la profundidad } \\
\text { del mercado por medio de la diferencia entre el bid (Compra) y ask } \\
\text { (Venta). }\end{array}$ \\
\hline Forwards TRM & $\begin{array}{l}\text { La tasa Forward TRM nos permite conocer las expectativas de los } \\
\text { agentes del mercado en un instante superior al } \mathrm{T}+1 \text {, donde sería una } \\
\text { fuente primaria de información para conocer la tendencia de corto plazo. }\end{array}$ \\
\hline $\begin{array}{c}\text { Dólar vs Pares del peso en } \\
\text { la Región }\end{array}$ & $\begin{array}{l}\text { La globalización lleva a ver el mundo como un todo y a su vez en el caso } \\
\text { de Latinoamérica es para los inversionistas del mundo una región, por lo } \\
\text { cual el comportamiento de pares como Pesos Mexicanos contra dólar, } \\
\text { Reales, chilenos y Sol peruano son altamente correlacionados con la tasa } \\
\text { de cambio en Colombia; por lo que es considerado como una variable de } \\
\text { impacto. }\end{array}$ \\
\hline PIB & $\begin{array}{l}\text { El producto interno bruto representa el crecimiento de una economía en } \\
\text { función de la producción de bienes y servicios, generada por nacionales } \\
\text { residentes en el país y por extranjeros residentes en el país, y excluye la } \\
\text { producción de nacionales residentes en el exterior. El indicador de } \\
\text { preferencia de la salud de una economía, para la estimación de la tasa de } \\
\text { cambio es importante comprender la actividad económica principal del } \\
\text { país, su ciclo y las perspectivas futuras. } \\
\text { Los inversionistas deben realizar seguimiento del crecimiento local y } \\
\text { global, tener un mapa de cómo se distribuirá y cuales es la tendencia. }\end{array}$ \\
\hline Inflación & $\begin{array}{l}\text { El costo de la calidad de vida en el país, es la preocupación principal del } \\
\text { Banco central; principalmente en economías como la colombiana donde } \\
\text { se tiene un target de inflación objetivo del } 2 \%-4 \% \text {. } \\
\text { La autoridad monetaria debe implementar políticas que permitan que la } \\
\text { inflación converja al target, sin embargo esas políticas tiene repercusión } \\
\text { económicas relevantes en términos de crecimiento y TRM, como lo } \\
\text { trabaja (Chavrro \& Grautoff, 2010). }\end{array}$ \\
\hline Tasa de interés local & $\begin{array}{l}\text { La tasa de interés de intervención es el instrumento de política monetaria } \\
\text { que el Banco central utiliza para buscar un equilibrio en la inflación, a su } \\
\text { vez es importante para los inversionistas el nivel de tasas de interés } \\
\text { porque es un catalizador de la economía en términos de liquidez y } \\
\text { rentabilidad real. Donde a niveles altos de tasa reales los inversionistas } \\
\text { extranjeros se pueden ver motivados a ingresar recursos. }\end{array}$ \\
\hline
\end{tabular}




\begin{tabular}{c}
\hline Variable \\
\hline \hline Tasa de interés EEUU \\
Política Monetaria \\
OP CALL - PUT, Tasa de \\
Intervención. \\
\hline
\end{tabular}

Cuenta Corriente

Flujos de Capital e Inversión Extranjera Directa

Calificación

Reservas Internacionales
La tasa de interés de la FED así como la de Colombia es una guía de inversión, dado que si hay una mayor tasa de interés en un país como EEUU, lo inversionistas prefieren fly to quality que realizar inversiones en países emergentes con mayor nivel de riesgo. La política monetaria de Estados Unidos es un factor de vital importancia para determinar hacia donde están yendo los flujos de capital. Al ser considerado como una de las economías más seguras, y sus bonos soberanos son considerados como bonos libres de riesgo, tal vez los bonos más seguros que existen.

Aplicación de los instrumentos de política monetaria, pueden mitigar la volatilidad de la tasa de cambio en el caso de las opciones put y call, el objetivo de esta intervención es disminuir el impacto antes choques de mercado, pero es difícil que la aplicación de estos instrumentos genere un cambio de trayectoria en la tasa de cambio.

Registro de las transacciones de Colombia con el resto de mundo, en otras palabras, es la relación entre las exportaciones e importaciones. La cuenta corriente un indicador de los movimientos reales de la oferta y demanda de divisas en nuestro país

Esta variable es finalmente la respuesta a una mejor perspectiva de riesgo y rentabilidad de los inversionistas extranjeros, donde la destinación de recursos para inversión migra a países como Colombia. La inversión extranjera es parte de la cuenta financiera dentro de la balanza de pagos, y su vez se constituye por inversión extranjera directa e inversión de portafolio.

La inversión extrajera de capital tiene mayor importancia, dado que permanece mucho más tiempo en el país y los flujos son mayores en contraste con la inversión de portafolio que es más cíclica y sensible a las condiciones globales de la economía de la región y el país.

El riesgo soberano es medido y clasificado en determinados rangos por empresas especializadas a nivel internacional, las cuales juegan un papel muy importante desde el punto de vista de los inversionistas, ya que se pronuncian sobre el riesgo soberano de los países que emiten deuda en los mercados internacionales, y sirven para determinar la prima de riesgo.

Para dicho fin, se evalúan aspectos coyunturales que puedan representar situaciones de riesgo para el inversionista, abarcando temas relacionados con lo económico, lo político, lo social y lo internacional (a nivel de legislaciones).

La calificación nación y los diferentes outlooks de las principales calificadoras, tienen un impacto indirecto en la tasa de cambio y esto se da porque cuando la calificación es positiva hay un mayor flujo de inversionistas extranjeros por lo contrario si es negativo el saldo de flujos negativo genera una depreciación de la moneda local. El resultado de la calificación tiene impacto en el variables como el PIB, Cuenta corriente y IED ${ }^{9}$ (Rojas \& Duque, 2014).

Las reservas internacionales están formadas por los activos externos que están bajo control de la autoridad monetaria, particularmente en Colombia el Banco de la República. El Banco mantiene reservas internacionales en cuantías que considera suficientes para intervenir en el mercado cambiario y para facilitar el acceso del Gobierno y del sector privado a los mercados internacionales de capitales.

Las reservas internacionales se han constituido en una herramienta esencial para los bancos centrales de todo el mundo. El mantenimiento de un adecuado nivel de las mismas sostiene la confianza en las medidas monetarias que adoptan y permite mantener la capacidad de intervención para moderar fluctuaciones excesivas en la unidad monetaria nacional (Gómez \& Hernández, 2011).

\footnotetext{
${ }^{9}$ Inversión extrajera directa.
} 


\begin{tabular}{cc}
\hline Variable & Descripción \\
\hline \hline
\end{tabular}
los que dispone el Banco para cumplir con el objetivo básico de mantener una tasa de inflación estable dentro del rango meta de largo plazo (2\% a 4\%) y lograr que el producto crezca alrededor de su tendencia de largo plazo. Por ejemplo, cuando una depreciación rápida del peso amenaza el logro de las metas de inflación, el Banco puede mitigar las presiones cambiarias mediante la venta de divisas en el mercado, evitando recargar el ajuste exclusivamente en la tasa de interés. Así mismo, el Banco puede intervenir en el mercado cambiario con el propósito de controlar movimientos atípicos o bruscos de la tasa de cambio, caracterizados por una alta volatilidad y por la ampliación significativa del margen entre el precio de compra y el de venta de la divisa, los cuales pueden influir sobre el desempeño de otros activos financieros conectados con el mercado cambiario y comprometer el objetivo del funcionamiento adecuado de los pagos internos y externos.

La economía colombiana en los últimos años ha tenido una alta dependencia en el sector minero energético, donde para el 2014 las exportaciones de este sector llegaron a pesar el 60\%; algunos analistas han llegado a catalogar esta dependencia con el nombre de enfermada holandesa ${ }^{10}$. Durante los años de bonanza del petróleo el cual alcanzo en referencias como la WTI valores por encima de los 100 dólares y una tasa de cambio que oscilaba entre los 1500 - 1900, el crecimiento de la economía colombiana se veía catapultada y los ingresos de la nación que en un alto porcentaje se componían de las utilidades de Ecopetrol ${ }^{11}$ (ver Gráfico 3).

Commodities (Petróleo) En este sentido en economías con alta dependencia a los precios de los commodities, en este escenario Petróleo; la tasa de cambio es la variable que primero se ajusta a un choque en el nivel de producción y precio internacional de Petróleo y se agudiza dado que Colombia es una economía pequeña y abierta y tiene un régimen cambiario en el que la tasa de cambio flota con ligeras intervenciones marginales del Banco de la República.

En la matriz de correlaciones se observa que para los diferentes periodos de análisis la correlación existente entre la TRM y Petróleo (Referencia genérica fuente Bloomberg) es inversa (ver Gráfico 3 y Tabla 1).

Esto quiere decir que cuando caen los precios de petróleo, la tasa de cambio se eleva porque ingresan menos dólares a la economía.

Los índices internacionales de deuda soberana como lo son índices de mercados soberanos de deuda creados por JP Morgan, conocidos como GBI-EM (GBI-EM Global Diversified y en el GBI-EM Global) y el Índices Internacionales MXEF. Son relevantes para el mercado dado que movimientos en la participación de Colombia en estos índices generan movimientos de flujo, estos índices son un referente a nivel mundial para los inversionistas. Estos índices son rebalanceados trimestralmente.

El conocimiento de los expertos realmente es una de las variables más importantes a pesar de los sesgos por subjetividad y conflictos de interés, el mercado de valores en el mundo está siendo cada vez más consiente que la visión a futuro no la da solo las cifras históricas y los modelos de proyección y pronóstico. Por ejemplo, hoy la economía global ha continuado con menores tasas de crecimiento desde la crisis suprime, por

\footnotetext{
10 Término que significa el crecimiento acelerado de un sector en la economía, en este caso el sector minero energético, crecimiento de ingresos por exportaciones de ese sector generan entradas desmedida de divisas al país y generan una dependencia que afecta la competitividad de la industria y el agro.

${ }^{11}$ Ecopetrol S.A. es la empresa más grande del país con una utilidad neta de \$15,4 billones registrada en 2011 y la principal compañía petrolera en Colombia. Por su tamaño, pertenece al grupo de las 40 petroleras más grandes del mundo y es una de las cuatro principales de Latinoamérica.(Ecopetrol S.A., 2016)
} 


\begin{tabular}{ll}
\hline Variable & \multicolumn{1}{c}{ Descripción } \\
\hline \hline & ciclo económico la tendencia sería una recuperación en el corto plazo, \\
& pero la realidad es que existen factores de incertidumbre, presiones \\
& económicas y políticas que no hacen tan factible este cambio de \\
& tendencia para los analistas. Inclusive en el caso local, la inflación en \\
& Colombia llegó a máximos históricos desde 1993 en una tendencia \\
& alcista, donde los modelos técnicos y los ciclos anticipaban una \\
& corrección superior a 200 pb para cierre de 2016, pero constantes \\
& choques en términos de transables, alimentos y energía no pintan un \\
& panorama tan claro de corrección para los especialistas del mercado. \\
& Es en este sentido que es importante considerar las visiones de los \\
& analistas dentro de los modelos de pronóstico y modelamiento de las \\
& tasas de interés, a su vez quizás no sea solo una visión acertada, lo que \\
lleva a las variables a ubicarse al nivel de las proyecciones de los \\
analistas: si no adicional a esto la psicología de los agentes ayuda a que \\
estos niveles sean mucho más realizables.
\end{tabular}

Un mercado se considera líquido cuando hay compradores y vendedores dispuestos a realizar operaciones de compra/venta en cualquier momento $\mathrm{y}$ a cualquier nivel de precios en el que cotice el activo. Una forma práctica de medir esta variable es con el spread entre las órdenes de compra y venta en un momento específico de tiempo, éste se construye con la diferencia entre la mejor orden de compra y venta (el precio más

Liquidez alto en el bid y más bajo en el ask respectivamente). Cuanto menor sea esta diferencia, más líquido estará el mercado en ese instante de tiempo.

La falta de liquidez hace que este spread entre el bid y ask sea más amplio, y por tanto es más probable que se generen movimientos de mayor rango en los precios, lo que aumenta la volatilidad en estos momentos de poca liquidez.

Los datos de bid y ask se pueden descargar desde la plataforma SET-FX en el intervalo de tiempo deseado.

La curva de rendimientos es una guía de inversión, los inversionistas extranjeros están motivados a invertir en economías como Colombia, dado que encuentran una prima en términos de tasa al comprar con las potencias mundiales que en la actualidad tienen tasas por debajo del $1 \%$, inclusive negativas.

Deuda Soberana

Es importante para el mercado identificar los movimientos en términos de deuda, liquidez y emisiones, dado que puede motivar la entrada o salida de flujos de inversión.

Este índice muestra la actualizad del dólar si se aprecia o deprecia frente a las principales monedas de la región, su función está basada en comparar el comportamiento del estadounidense frente a las principales seis divisas del mundo, euro, yen japonés, libra esterlina, dólar canadiense, corona sueca y el franco suizo.

Dollar Index DXY

La composición del índice actualmente es dólar-euro (57.6\%), dólar-yen japonés (13.6\%), dólar-libra esterlina (11.9\%), dólar-dólar canadiense (9.1\%), dólar-corona sueca (4.2\%), dólar-franco suizo (3.6\%).

Este índice permite a los operadores tener señales del mercado rápidas para prever cómo va reaccionar la moneda local.

La tasa de equilibrio está expresada en función de los valores sostenibles de los fundamentales macroeconómicos en el tiempo, existen diferentes metodologías para su cálculo como la teoría de paridad del poder adquisitivo (PPA), postula que el precio doméstico de los bienes está determinado por el precio internacional medido en moneda local, y que la tasa de cambio nominal debe compensar los diferenciales de inflación entre países. Ello lleva a una tasa de cambio real constante en la versión relativa de la PPA o igual a 1 en su versión absoluta. Sin embargo la

\footnotetext{
12 Puntos básicos, inflación actual 3.97\% octubre de 2017, pronósticos del gobierno cierre de 2017 dentro
} del rango meta, mientras que el mercado espera que cierre alrededor de $4.15 \%$. 


\begin{tabular}{|c|c|}
\hline Variable & Descripción \\
\hline & $\begin{array}{l}\text { historia muestra que la tasa de equilibrio no es estática en el tiempo } \\
\text { (Echavarría et al., 2007). } \\
\text { Autores como Echavarría et al. (2007) obtienen un efecto importante } \\
\text { para dicha variable, pero éste desaparece en el muy largo plazo. Otros } \\
\text { autores afirman que la relación entre la tasa de cambio nominal y real } \\
\text { simplemente indica que, a diferencia de lo que sugieren los modelos } \\
\text { nominales, los shocks reales también afectan la tasa de cambio nominal } \\
\text { (Krugman, Obstfeld, \& Melitz, 2012). }\end{array}$ \\
\hline Noticias & $\begin{array}{l}\text { En general las noticias locales e internacionales con impacto económico } \\
\text { y coyuntural generan choques en los niveles de la tasa de cambio, } \\
\text { algunos analistas se han preocupado por generar modelos con choques } \\
\text { por información. } \\
\text { Existen diferentes tipos de noticias como las imprevistas de coyunturas, } \\
\text { conflictos, descubrimientos y desastres naturales, entre otros y noticias } \\
\text { de revelación de datos que el mercado conoce con antelación la fecha en } \\
\text { la que se va a dar información como son la revelación de indicadores } \\
\text { macroeconómicos, la aprobación de leyes y la aplicación de políticas. } \\
\text { Es importante tener en cuenta cómo se interpretan estas noticias por el } \\
\text { mercado. No es tan importante si la noticia fue mala o buena, sino que } \\
\text { tan alejada fue la noticia con respecto a lo esperado por el mercado. Los } \\
\text { mercados financieros descuentan con el movimiento en los precios el } \\
\text { resultado de estas noticias antes de que sean publicadas; si el mercado } \\
\text { espera en dato malo en la próxima noticia de inflación, lo más común es } \\
\text { que desde meses o días atrás el mercado haya descontado los efectos de } \\
\text { esta noticia, por tanto, cuando salga en línea con lo que el mercado } \\
\text { esperaba, lo más probable es que no se presenten cambios significativos } \\
\text { en las cotizaciones de los activos. } \\
\text { Así pues, lo que genera más volatilidad y cambio en los precios, son las } \\
\text { noticias que se alejan mucho de lo que el mercado en general está } \\
\text { esperando. Este efecto es posible medirlo mediante la construcción de } \\
\text { una variable de sorpresa, que cuantifica cuánto sorprendió al mercado } \\
\text { una noticia. }\end{array}$ \\
\hline ras Variables con & $\begin{array}{l}\text { eo, salarios, confianza del consumidor e índice de precios de productor no } \\
\text { la tendencia por sí solos, pero son incluidos de forma indirecta dentro de }\end{array}$ \\
\hline
\end{tabular}

Fuente: Elaboración propia. 


\section{Anexo 2. Correlograma Retornos diarios TRM.}

Con un nivel de confianza del 5\% se rechaza la hipótesis nula de no autocorrelación serial, dado que todos los p-valor son igual a cero.

\begin{tabular}{|c|c|c|c|c|c|c|}
\hline Autocorrelación & $\begin{array}{c}\text { Correlación } \\
\text { Parcial }\end{array}$ & \multicolumn{2}{|c|}{$\mathrm{AC}$} & PAC & Q-Stat & Prob \\
\hline 吋 & 吋 & 1 & 0.19 & 0.19 & 63.40 & 0.00 \\
\hline$\sqrt{1}$ & $\sqrt{1}$ & 2 & -0.02 & -0.06 & 64.31 & 0.00 \\
\hline 1 & 1 & 3 & -0.02 & 0.00 & 64.77 & 0.00 \\
\hline$\|_{1}$ & | & 4 & 0.00 & 0.00 & 64.77 & 0.00 \\
\hline 1 & 1 & 5 & 0.00 & 0.00 & 64.77 & 0.00 \\
\hline | & 1 & 6 & 0.00 & 0.01 & 64.80 & 0.00 \\
\hline 1 & 1 & 7 & -0.02 & -0.02 & 65.42 & 0.00 \\
\hline 监 & 巾 & 8 & 0.03 & 0.04 & 67.15 & 0.00 \\
\hline 1 & 㠶 & 9 & 0.06 & 0.05 & 73.29 & 0.00 \\
\hline 1 & 1 & 10 & 0.00 & -0.02 & 73.31 & 0.00 \\
\hline q & 1 & 11 & -0.03 & -0.03 & 75.00 & 0.00 \\
\hline 1 & 1 & 12 & -0.02 & -0.01 & 75.70 & 0.00 \\
\hline 中 & 中 & 13 & 0.01 & 0.02 & 76.02 & 0.00 \\
\hline 中 & 中 & 14 & 0.02 & 0.01 & 76.81 & 0.00 \\
\hline 1 & 11 & 15 & 0.00 & -0.01 & 76.81 & 0.00 \\
\hline " & 1 & 16 & 0.00 & 0.00 & 76.81 & 0.00 \\
\hline 1 & 1 & 17 & 0.00 & -0.01 & 76.84 & 0.00 \\
\hline 1 & 1 & 18 & -0.02 & -0.02 & 77.21 & 0.00 \\
\hline '1 & "' & 19 & 0.01 & 0.01 & 77.26 & 0.00 \\
\hline 中 & " & 20 & 0.04 & 0.04 & 80.12 & 0.00 \\
\hline
\end{tabular}

Fuente: Elaboración propia.

\section{Anexo 3. Comparación Modelos ARIMA.}

Se selecciona el modelo ARIMA $(9,1,0)$ como el mejor modelo para la estimación del par USD/COP.

\begin{tabular}{lrr}
\hline \multicolumn{1}{c}{ Modelo / Criterios } & ARIMA $(9,1,0)$ & ARIMA $(1,1,0)$ \\
\hline \hline R-squared & 0.009248 & 0.004608 \\
Adjusted R-squared & 0.007453 & 0.003406 \\
Akaike info criterion & -7.369054 & -7.366083 \\
Schwarz criterion & -7.346222 & -7.346512 \\
Hannan-Quinn criter. & -7.360592 & -7.358829 \\
Durbin-Watson stat & 2.004227 & 2.014018 \\
\hline \multicolumn{2}{c}{ Fuente: Elaboración propia. }
\end{tabular}




\section{Anexo 4. Correlograma Residuos al cuadrado modelo ARIMA.}

Se comprueba el efecto ARCH con un p-valor de 0 , se rechaza la hipótesis nula de no presencia de efecto ARCH.

\begin{tabular}{|c|c|c|c|c|c|c|}
\hline Autocorrelación & $\begin{array}{c}\text { Correlación } \\
\text { Parcial } \\
\end{array}$ & & $\mathrm{AC}$ & PAC & Q-Stat & Prob \\
\hline 吅 & 吅 & 1 & 0.17 & 0.17 & 49.85 & 0.00 \\
\hline 吅 & 卢 & 2 & 0.16 & 0.13 & 90.20 & 0.00 \\
\hline 口 & פ & 3 & 0.19 & 0.15 & 149.46 & 0.00 \\
\hline طا & ط & 4 & 0.15 & 0.09 & 187.80 & 0.00 \\
\hline Г & $\sqrt{10}$ & 5 & 0.10 & 0.03 & 203.47 & 0.00 \\
\hline 吅 & 㠼 & 6 & 0.11 & 0.05 & 224.59 & 0.00 \\
\hline 口 & 卢 & 7 & 0.19 & 0.14 & 286.46 & 0.00 \\
\hline ط & p & 8 & 0.11 & 0.03 & 307.50 & 0.00 \\
\hline طا & קי & 9 & 0.12 & 0.05 & 331.64 & 0.00 \\
\hline 㞋 & 同 & 10 & 0.12 & 0.04 & 356.85 & 0.00 \\
\hline 吅 & 陑 & 11 & 0.13 & 0.05 & 386.48 & 0.00 \\
\hline 吅 & 而 & 12 & 0.12 & 0.04 & 409.39 & 0.00 \\
\hline 口 & 吋 & 13 & 0.19 & 0.12 & 471.71 & 0.00 \\
\hline 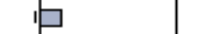 & 陌 & 14 & 0.16 & 0.06 & 513.51 & 0.00 \\
\hline 可 & 阳 & 15 & 0.17 & 0.08 & 561.12 & 0.00 \\
\hline 吕 & 1) & 16 & 0.14 & 0.03 & 594.19 & 0.00 \\
\hline 原 & $\sqrt{1}$ & 17 & 0.11 & 0.00 & 615.24 & 0.00 \\
\hline 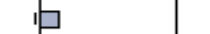 & 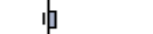 & 18 & 0.15 & 0.05 & 653.13 & 0.00 \\
\hline 尚 & $\sqrt{1}$ & 19 & 0.10 & 0.00 & 670.47 & 0.00 \\
\hline 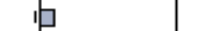 & ו| & 20 & 0.11 & 0.01 & 690.71 & 0.00 \\
\hline
\end{tabular}

Fuente: Elaboración propia.

Anexo 5. Correlograma de los residuos y los residuos al cuadrado Modelo ARIMA $(9,1,0)$ - GARCH $(1,1)$.

Con un nivel de confianza del $5 \%$ se acepta la hipótesis nula de no autocorrelación serial, dado que todos los p-valor son mayores a 5\%, los residuos del modelo no están autorrelacionados y son ruido blanco.

\begin{tabular}{|c|c|c|c|c|c|c|}
\hline \multicolumn{7}{|c|}{ Residuos } \\
\hline \multirow{2}{*}{ Autocorrelación } & \multicolumn{6}{|l|}{ Correlación } \\
\hline & Parcial & & $\mathrm{AC}$ & PAC & Q-Stat & Prob \\
\hline 川 & 悄 & 1 & 0.00 & 0.00 & 0.01 & \\
\hline 巾 & 巾 & 2 & 0.04 & 0.04 & 3.06 & \\
\hline " & " & 3 & 0.00 & 0.00 & 3.06 & 0.08 \\
\hline | & | & 4 & 0.00 & -0.01 & 3.08 & 0.22 \\
\hline | & إ & 5 & 0.00 & 0.00 & 3.08 & 0.38 \\
\hline 少 & 川 & 6 & 0.01 & 0.01 & 3.29 & 0.51 \\
\hline 11 & |' & 7 & 0.00 & 0.00 & 3.29 & 0.66 \\
\hline 少 & $\|$ & 8 & 0.02 & 0.02 & 4.07 & 0.67 \\
\hline 1 & 1 & 9 & 0.01 & 0.01 & 4.13 & 0.77 \\
\hline q & q & 10 & -0.04 & -0.05 & 7.24 & 0.51 \\
\hline 巾 & 巾 & 11 & 0.05 & 0.05 & 11.60 & 0.24 \\
\hline 1 & 1 & 12 & -0.03 & -0.03 & 13.14 & 0.22 \\
\hline 川 & 川 & 13 & 0.01 & 0.01 & 13.43 & 0.27 \\
\hline 巾 & 巾 & 14 & 0.03 & 0.03 & 14.66 & 0.26 \\
\hline " & " & 15 & 0.00 & 0.00 & 14.69 & 0.33 \\
\hline 川 & 川 & 16 & 0.01 & 0.01 & 15.02 & 0.38 \\
\hline d & 1 & 17 & -0.02 & -0.02 & 15.73 & 0.40 \\
\hline d & 1 & 18 & -0.01 & -0.01 & 15.99 & 0.45 \\
\hline 1 & 1 & 19 & -0.02 & -0.02 & 16.50 & 0.49 \\
\hline 巾 & 巾 & 20 & 0.04 & 0.04 & 18.80 & 0.41 \\
\hline
\end{tabular}

\begin{tabular}{|c|c|c|c|c|c|c|}
\hline \multicolumn{7}{|c|}{ Residuos al Cuadrado } \\
\hline \multirow{2}{*}{ Autocorrelación } & \multicolumn{6}{|c|}{ Correlación } \\
\hline & Parcial & & $\mathrm{AC}$ & PAC & Q-Stat & Prob \\
\hline 㠴 & 㠸 & 1 & 0.01 & 0.01 & 0.29 & 0.59 \\
\hline 1) & 巾 & 2 & 0.05 & 0.05 & 4.12 & 0.13 \\
\hline 州 & 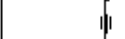 & 3 & 0.03 & 0.03 & 5.35 & 0.15 \\
\hline 少 & 川 & 4 & 0.00 & -0.01 & 5.37 & 0.25 \\
\hline$\sqrt{1}$ & $\sqrt{1}$ & 5 & 0.02 & 0.02 & 5.87 & 0.32 \\
\hline 1 & 1 & 6 & -0.04 & -0.04 & 8.23 & 0.22 \\
\hline in & 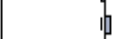 & 7 & 0.03 & 0.02 & 9.24 & 0.24 \\
\hline 1 & 1 & 8 & -0.01 & 0.00 & 9.28 & 0.32 \\
\hline$\|_{1}$ & d & 9 & 0.01 & 0.01 & 9.51 & 0.39 \\
\hline$\|$ & $\|_{1}$ & 10 & -0.02 & -0.02 & 10.26 & 0.42 \\
\hline$\|_{1}$ & $\|_{1}$ & 11 & 0.00 & 0.01 & 10.28 & 0.51 \\
\hline di & 1 & 12 & -0.01 & -0.01 & 10.51 & 0.57 \\
\hline$\|$ & $\|$ & 13 & -0.02 & -0.02 & 11.46 & 0.57 \\
\hline 1) & 1) & 14 & 0.03 & 0.03 & 12.63 & 0.56 \\
\hline N11 & 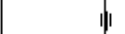 & 15 & -0.01 & -0.01 & 12.88 & 0.61 \\
\hline 1 & 1 & 16 & 0.02 & 0.02 & 13.52 & 0.63 \\
\hline | & $\|$ & 17 & 0.01 & 0.02 & 13.86 & 0.68 \\
\hline$\sqrt{1}$ & 11 & 18 & -0.02 & -0.02 & 14.47 & 0.70 \\
\hline d & $d$ & 19 & -0.03 & -0.03 & 15.94 & 0.66 \\
\hline 1 & 1 & 20 & -0.04 & -0.03 & 18.27 & 0.57 \\
\hline
\end{tabular}

Fuente: Elaboración propia. 
Anexo 6. Correlograma Residuos al cuadrado Modelo ARIMAX.

Se comprueba el efecto ARCH con un p-valor de 0, se rechaza la hipótesis nula de no presencia de efecto ARCH.

\begin{tabular}{|c|c|c|c|c|c|c|}
\hline Autocorrelación & $\begin{array}{c}\text { Correlación } \\
\text { Parcial } \\
\end{array}$ & & $\mathrm{AC}$ & PAC & Q-Stat & Prob \\
\hline り & 曰 & 1 & 0.18 & 0.18 & 53.87 & 0.00 \\
\hline 包 & 吕 & 2 & 0.20 & 0.17 & 119.03 & 0.00 \\
\hline صـ" & 吕 & 3 & 0.22 & 0.17 & 196.33 & 0.00 \\
\hline 回 & (1) & 4 & 0.14 & 0.06 & 227.93 & 0.00 \\
\hline 官 & 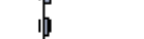 & 5 & 0.12 & 0.04 & 251.70 & 0.00 \\
\hline 官 & 少 & 6 & 0.11 & 0.03 & 272.19 & 0.00 \\
\hline 占 & 尚 & 7 & 0.17 & 0.11 & 318.82 & 0.00 \\
\hline 占 & 19 & 8 & 0.13 & 0.05 & 345.42 & 0.00 \\
\hline 卢 & 巾 & 9 & 0.11 & 0.03 & 367.26 & 0.00 \\
\hline 卢 & $\sqrt{1}$ & 10 & 0.08 & -0.02 & 376.70 & 0.00 \\
\hline 肾 & 川 & 11 & 0.09 & 0.02 & 389.92 & 0.00 \\
\hline קו & 巾 & 12 & 0.10 & 0.04 & 405.58 & 0.00 \\
\hline 尚 & 中 & 13 & 0.12 & 0.07 & 429.22 & 0.00 \\
\hline 口 & 中 & 14 & 0.15 & 0.08 & 464.90 & 0.00 \\
\hline 占 & 巾 & 15 & 0.10 & 0.02 & 482.98 & 0.00 \\
\hline ص & 中 & 16 & 0.15 & 0.06 & 520.06 & 0.00 \\
\hline 吋 & 中 & 17 & 0.13 & 0.04 & 547.99 & 0.00 \\
\hline 阳 & 1 & 18 & 0.09 & 0.01 & 562.99 & 0.00 \\
\hline 巾 & 4 & 19 & 0.06 & -0.04 & 569.02 & 0.00 \\
\hline 吋 & $\|$ & 20 & 0.10 & 0.01 & 584.09 & 0.00 \\
\hline
\end{tabular}

Fuente: Elaboración propia.

Anexo 7. Correlograma de los residuos y los residuos al cuadrado Modelo ARIMAX (9,1,0) - GARCH (1,1).

Con un nivel de confianza del $5 \%$ se acepta la hipótesis nula de no autocorrelación serial, dado que todos los P-Valor son mayores a 5\%, los residuales del modelo no están autorrelacionados y son ruido blanco.

\begin{tabular}{|c|c|c|c|c|c|}
\hline \multicolumn{6}{|c|}{ Residuos } \\
\hline Autocorrelación & $\begin{array}{l}\text { Correlación } \\
\text { Parcial }\end{array}$ & AC & PAC & Q-Stat & Prob \\
\hline
\end{tabular}

|rrrrrr

\begin{tabular}{|c|c|c|c|c|c|}
\hline \multicolumn{6}{|c|}{ Residuos al Cuadrado } \\
\hline & Correlación & & & & \\
\hline Autocorrelacion & Parcial & AC & PAC & Q-Stat & Prob \\
\hline
\end{tabular}

\begin{tabular}{|c|c|c|c|c|c|c|}
\hline 11 & 中 & 1 & 0.02 & 0.02 & 0.45 & 0.50 \\
\hline & 占 & 2 & 0.05 & 0.05 & 4.82 & 0.09 \\
\hline & $\sqrt{10}$ & 3 & 0.03 & 0.03 & 6.56 & 0.09 \\
\hline & $\sqrt{1}$ & 4 & 0.00 & 0.00 & 6.57 & 0.16 \\
\hline & N & 5 & 0.01 & 0.01 & 6.84 & 0.23 \\
\hline & d & 6 & -0.03 & -0.03 & 8.09 & 0.23 \\
\hline & $\|$ & 7 & 0.02 & 0.02 & 8.77 & 0.27 \\
\hline & d & 8 & -0.01 & -0.01 & 9.06 & 0.34 \\
\hline & 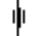 & 9 & 0.01 & 0.01 & 9.18 & 0.42 \\
\hline & d & 10 & -0.03 & -0.03 & 10.52 & 0.40 \\
\hline & N & 11 & 0.01 & 0.01 & 10.71 & 0.47 \\
\hline & $\|_{1}$ & 12 & 0.00 & 0.00 & 10.72 & 0.55 \\
\hline 1 & (1 & 13 & -0.02 & -0.02 & 11.28 & 0.59 \\
\hline & 巾 & 14 & 0.03 & 0.03 & 12.86 & 0.54 \\
\hline & "' & 15 & -0.01 & -0.01 & 13.01 & 0.60 \\
\hline & 巾 & 16 & 0.03 & 0.03 & 14.50 & 0.56 \\
\hline & $\|_{1}$ & 17 & 0.00 & 0.00 & 14.51 & 0.63 \\
\hline & $d_{1}$ & 18 & -0.02 & -0.03 & 15.44 & 0.63 \\
\hline & di & 19 & -0.03 & -0.04 & 17.33 & 0.57 \\
\hline & & 20 & -0.05 & -0.04 & 20.91 & 0.40 \\
\hline
\end{tabular}

Fuente: Elaboración propia. 